\title{
Exploring the missing heritability in subjects with hearing loss, enlarged vestibular aqueducts, and a single or no pathogenic SLC26A4 variant
}

\author{
Jeroen J. Smits ${ }^{1,2,3}$ - Suzanne E. de Bruijn ${ }^{2,3}$ - Cornelis P. Lanting ${ }^{1}$ (D) Jaap Oostrik ${ }^{1,3} \cdot$ Luke O'Gorman $^{2}$. \\ Tuomo Mantere ${ }^{2,4}$. DOOFNL Consortium • Frans P. M. Cremers ${ }^{2,3}$. Susanne Roosing ${ }^{2,3} \cdot$ Helger G. Yntema ${ }^{2}$. \\ Erik de Vrieze ${ }^{1,3} \cdot$ Ronny Derks ${ }^{2} \cdot$ Alexander Hoischen $^{2,5,6,7} \cdot$ Sjoert A. H. Pegge ${ }^{8} \cdot$ Kornelia Neveling $^{2}$. \\ Ronald J. E. Pennings ${ }^{1,3} \cdot$ Hannie Kremer ${ }^{1,2,3}$ (i)
}

Received: 30 May 2021 / Accepted: 9 August 2021 / Published online: 19 August 2021

(c) The Author(s) 2021, corrected publication 2021

\begin{abstract}
Pathogenic variants in SLC26A4 have been associated with autosomal recessive hearing loss (arHL) and a unilateral or bilateral enlarged vestibular aqueduct (EVA). SLC26A4 is the second most frequently mutated gene in arHL. Despite the strong genotype-phenotype correlation, a significant part of cases remains genetically unresolved. In this study, we investigated a cohort of 28 Dutch index cases diagnosed with HL in combination with an EVA but without (M0) or with a single (M1) pathogenic variant in SLC26A4. To explore the missing heritability, we first determined the presence of the previously described EVA-associated haplotype (Caucasian EVA (CEVA)), characterized by 12 single nucleotide variants located upstream of SLC26A4. We found this haplotype and a delimited V1-CEVA haplotype to be significantly enriched in our M1 patient cohort (10/16 cases). The CEVA haplotype was also present in two M0 cases (2/12). Short- and long-read whole genome sequencing and optical genome mapping could not prioritize any of the variants present within the CEVA haplotype as the likely pathogenic defect. Short-read whole-genome sequencing of the six M1 cases without this haplotype and the two M0/CEVA cases only revealed previously overlooked or misinterpreted splice-altering SLC26A4 variants in two cases, who are now genetically explained. No deep-intronic or structural variants were identified in any of the M1 subjects. With this study, we have provided important insights that will pave the way for elucidating the missing heritability in M0 and M1 SLC26A4 cases. For pinpointing the pathogenic effect of the CEVA haplotype, additional analyses are required addressing defect(s) at the RNA, protein, or epigenetic level.
\end{abstract}

\section{Introduction}

SLC26A4 encodes the transmembrane anion transporter pendrin and is most abundantly expressed in the inner ear, thyroid gland, kidney, and airways epithelia (Everett et al. 1997, 1999; Pedemonte et al. 2007; Royaux et al. 2000, 2001). The 780 amino acid protein is part of the solute carrier

Jeroen J. Smits and Suzanne E. de Bruijn contributed equally to this work.

The complete list of collaborators for DOOFNL Consortium are given in acknowlegment section.

Hannie Kremer

Hannie.Kremer@radboudumc.nl

Extended author information available on the last page of the article family 26 and plays a pivotal role in chloride, bicarbonate and iodine transport. In the inner ear, pendrin functions as a $\mathrm{Cl}^{-} / \mathrm{HCO}_{3}{ }^{-}$exchanger. The protein is expressed in the epithelial cells of the cochlea (outer sulcus and spindle cells), the vestibular labyrinth (transitional cells), and the endolymphatic duct and sac (mitochondrial-rich cells) (Wangemann 2011; Wangemann et al. 2007). Expression of pendrin is essential for the development of the (murine) auditory and vestibular system and for maintaining ion homeostasis in the endolymphatic fluid and the endocochlear potential (Dou et al. 2004; Everett et al. 1999; Royaux et al. 2003; Wangemann 2011).

Defects in SLC26A4 are among the most frequent causes (up to $10 \%$ ) of early-onset autosomal recessive hearing loss (arHL); non-syndromic DFNB4 (MIM: 600,791) and Pendred syndrome (MIM: 274,600) (Sloan-Heggen et al. 2016). Individuals carrying biallelic pathogenic SLC26A4 
variants are affected by variable, often progressive and predominantly sensorineural HL with a congenital or childhood-onset (Lee et al. 2014; Suzuki et al. 2007). In Pendred syndrome, the HL phenotype is accompanied by an iodine organification defect that can lead to thyroid goiter (Fraser 1965). In individuals affected by either syndromic or nonsyndromic SLC26A4-associated HL, a unilateral or bilateral enlarged vestibular aqueduct (EVA) is observed, which is the most common imaging abnormality in individuals with HL (van Beeck Calkoen et al. 2017, 2018). In some cases, EVA can be part of Mondini dysplasia: an inner ear malformation that includes both EVA and cochlear incomplete partition type II. Although Mondini dysplasia can be observed in both Pendred syndrome and DFNB4 cases, cases with the syndromic type of HL are more likely to present Mondini dysplasia than those with non-syndromic HL (Forli et al. 2021; Mey et al. 2019).

Pathogenic variants in SLC26A4 have a loss-of-function effect, leading to malfunctioning of the pendrin ion transporter. Besides the antenatal formation of an EVA, this ultimately leads to acidification of the endolymphatic fluids in the inner ear during embryonic development (Griffith and Wangemann 2011; Wangemann 2011). Although the exact molecular pathogenic mechanism remains to be elucidated, the lack of pendrin function ultimately leads to degeneration of the sensory cells in the inner ear (Wangemann 2011).

Despite the strong association between defects of SLC26A4 and HL combined with an EVA, genetic screening of subjects with this combination of defects often does not reveal biallelic pathogenic variants in SLC26A4 (coined M2). Cohort studies report that $14-31 \%$ of the subjects with an EVA and HL carry a monoallelic pathogenic variant in SLC26A4 (M1), whereas in 10-65\% of the subjects, no potentially pathogenic variant in the coding or splice site regions of the gene can be identified (M0) (Azaiez et al. 2007; Choi et al. 2009; Mey et al. 2019). Segregation analyses performed in family members of M1 subjects, however, do suggest that in $98 \%$ of M1 subjects an unidentified or unrecognized variant is present on the trans SLC26A4 allele (Azaiez et al. 2007; Pryor et al. 2005). In line with this hypothesis, Chattaraj and coworkers reported a haplotype, referred to as the Caucasian EVA (CEVA) haplotype, that was present in 13 of $16(81 \%)$ of the studied M1 families and that was also enriched in M0 subjects (Chattaraj et al. 2017). The haplotype is defined by the combination of 12 single nucleotide polymorphisms (SNPs; allele frequency (AF) $1.9-4.0 \%$ ) spanning a $613 \mathrm{~kb}$ region. The 12 SNPs are located within a region of linkage disequilibrium that extends from upstream of PRKAR2B to intron 3 of $S L C 26 A 4$ and are either intergenic or intronic of the genes $S L C 26 A 4$, BCAP29, DUS4L, COG5, GPR22, HBP1, PRKAR2B and PIK3CG (Chattaraj et al. 2017). The true genetic defect of the CEVA allele has not been identified yet, but it cannot be excluded that a potential defect was missed due to the technical limitations of short-read sequencing and other standard-of-care tests. The CEVA haplotype was reported to be associated with a less severe HL phenotype as compared to variants in the protein-coding or splice site regions of SLC26A4 (Chao et al. 2019).

We investigated a Dutch cohort of M1 and M0 subjects with HL and a unilateral or bilateral EVA. All subjects were tested for the presence of the CEVA haplotype, and wholegenome sequencing (WGS) was performed to detect potentially missed single nucleotide variants (SNVs), structural variants (SVs), and regulatory or deep-intronic variants. Long-read sequencing and optical genome mapping were performed to reveal a potentially missed SV located on the CEVA haplotype. Variants located within the haplotype were subjected to in silico analyses to investigate potential effects on the regulation of SLC26A4 expression or on splicing. With this study, we provided further insights into SLC26A4-associated disease.

\section{Material and methods}

\section{Inclusion criteria and clinical evaluation}

Subjects diagnosed with unilateral or bilateral HL and a unilateral or bilateral EVA on CT or MRI and for whom medical genetic testing only revealed a heterozygous (M1, $n=16$ ) or no pathogenic variant (M0, $n=12)$ in SLC26A4 were eligible to participate in this study. A retrospective cohort of nine subjects with confirmed pathogenic (biallelic) variants in $S L C 26 A 4$ was added as a reference cohort (Online Resource Table S1).

Medical history was taken from all participants and special attention was paid to non-genetic causes of HL. Results of pure tone, speech, and brainstem evoked response audiometry, performed in a sound-attenuated booth, were collected. Air and bone conduction pure tone thresholds were determined for frequencies ranging from 0.25 to $8 \mathrm{kHz}$. Threshold estimates based on brainstem evoked response audiometry were used when pure tone audiometry was not available. Individuals were considered affected when pure tone thresholds for at least three frequencies were above the frequency-specific $95^{\text {th }}$ percentile of age- and sex-specific thresholds (ISO 7029:2017) for the best hearing ear. In the Netherlands, routine newborn hearing screening is carried out by the detection of transient evoked otoacoustic emissions (van der Ploeg et al. 2012). When available, these data were used to determine whether the HL was congenital.

Previously performed CT and MRI scans were retrieved and reassessed by an experienced neuroradiologist (SAHP). An EVA was defined as a vestibular aqueduct that measured $\geq 2 \mathrm{~mm}$ at the operculum and/or $\geq 1 \mathrm{~mm}$ at the midpoint 
(Boston et al. 2007), in accordance with previously published reports on this topic (Chao et al. 2019; Chattaraj et al. 2017). Analyses of pair-wise differences between patient groups were performed with R (R Foundation, Auckland, New Zealand) using multivariate linear regression analysis (using lsmeans 2.3.0) with a correction for multiple comparisons using the Holm method (Lenth 2016).

\section{Next-generation sequencing and variant interpretation}

Genomic DNA was isolated from peripheral blood lymphocytes and analyzed by molecular inversion probe (MIP) sequencing, whole-exome sequencing (WES) or wholegenome sequencing (WGS) (Online Resource Table S2). For WES, exome enrichment was performed using the Agilent SureSelect Human All Exome V4 or V5 kits according to the manufacturer's instructions. Subsequently, sequencing was executed on an Illumina HiSeq system by BGI Europe (Copenhagen, Denmark), with a minimal coverage of $20 \times$ for $93.77 \%$ of the targets and an average coverage of $>100$ reads. Read mapping along the hg19 reference genome (GRCh37/ hg19) and variant calling was performed using BWA V.0.78 (Li and Durbin 2009) and GATK HaplotypeCaller V.3.3 (McKenna et al. 2010), respectively. An in-house developed pipeline was used for variant annotation and copy number variant (CNV) detection was performed using CoNIFER V.0.2.2.3 (Krumm et al. 2012). WGS was performed by BGI (Hongkong, China) on a BGISeq500 using a $2 \times 100$ bp paired-end module, with a minimal median coverage of 30-fold per genome. Read mapping (GRCh37/hg19) and variant calling was performed as described for WES. Structural variants (SVs) were called using the Manta Structural Variant Caller V.1.1.0 (SV detection based on paired end and split read evidence) (Chen et al. 2016) and CNVs using Control-FREEC (CNV detection based on alterations in read depth) (Boeva et al. 2012). MIP design, sequencing and data analysis were performed as previously described (de Bruijn et al. 2021; Neveling et al. 2017). MIPs were designed to cover exons and exon-intron boundaries of a panel of 120 HL genes (Online Resource Table S3). For each targeted region an average coverage of $>500$ reads was obtained. A minimal coverage of $20 \times$ was reached for $91.78 \%$ of the MIPs. CNV detection for SLC26A4 was performed using a read coverage analysis as previously described (Khan et al. 2020). Additionally, coding and splice site regions of FOXII and the regions harboring reported pathogenic variants in EPHA2 were sequenced using Sanger sequencing as previously described (Wesdorp et al. 2018), since these genes are not included in the MIP panel. Primer sequences and PCR conditions are available upon request.

Variant prioritization was based on an AF of $\leq 0.5 \%$ [gnomAD V2.1.1 (Karczewski et al. 2019) and our in-house exome database $(\sim 15,000$ alleles $)]$, unless specified otherwise. Variant visualization was performed using the IGV software V.2.4 (Broad Institute, Cambridge, MA, USA) (Robinson et al. 2011). Interpretation of missense variants was performed using the in silico tools CADD-PHRED ( $\geq 15$ ) (Kircher et al. 2014), SIFT $(\leq 0.05)$ (Vaser et al. 2015), PolyPhen-2 ( $\geq 0.450$ ) (Adzhubei et al. 2010) and MutationTaster (deleterious) (Schwarz et al. 2014) to predict potentially deleterious effects. Variants were prioritized if a deleterious effect was predicted by at least two of these tools. Candidate variants were validated by Sanger sequencing and segregation analysis was performed when DNA of family members was available. Primer sequences and PCR conditions are available upon request. Potential effects on splicing of missense, synonymous and intronic variants were assessed using the deep-learning splice prediction algorithm SpliceAI ( $\geq 0.1$ ) (Jaganathan et al. 2019). The maximum distance between the variant and potential gained or lost splice sites was set to $1000 \mathrm{bp}$. Predicted splice altering defects were evaluated using an in vitro splice assay in HEK293T cells as previously described (Sangermano et al. 2018).

\section{Detection of the CEVA haplotype}

Initial identification of the CEVA haplotype was performed with SNP-genotyping by Sanger sequencing in index cases for whom parental DNA was available for segregation analysis. Subsequently, the corresponding VNTR marker haplotype was determined in CEVA-positive families. For additional cases, VNTR marker analysis was performed to enable a fast and cost-effective detection of the CEVA haplotype. For the VNTR marker analysis, DNA segments were amplified by employing touchdown PCR, and subsequent analysis was carried out on an ABI Prism 3730 Genetic Analyzer (Applied Biosystems, Foster City, CA, USA). Genomic positions of the markers were determined using the UCSC genome browser (GRCh37/hg19) (Kent et al. 2002). Alleles were assigned with the GeneMarker software (V.2.6.7, SoftGenetics, State College, PA, USA) according to the manufacturer's instructions. When an individual was suspected of carrying the CEVA haplotype based on VNTR-marker alleles, SNP genotyping by Sanger sequencing was performed to confirm the presence of the twelve SNPs that are located within the haplotype (Chattaraj et al. 2017). SNPphasing was performed if DNA samples of family members was available.

\section{Optical genome mapping}

Optical genome mapping (Bionano Genomics, San Diego, CA, USA) was performed as previously described (Mantere et al. 2021; Neveling et al. 2021). Ultra-high molecular weight DNA was isolated from whole peripheral blood 
(collected in EDTA tubes) using the SP Blood \& Cell Culture DNA Isolation Kit (Bionano Genomics, San Diego, CA, USA). CTTAAG labeling was performed using the DLS (Direct Label and Stain) DNA Labeling Kit (Bionano Genomics, San Diego, CA, USA) and the labeled sample was analyzed using a $3 \times 1300 \mathrm{~Gb}$ Saphyr chip (G2.3) on a Saphyr instrument (Bionano Genomics, San Diego, CA, USA). An effective coverage of $124 \times$ was reached, with a label density of 14.63/100 kb and an average N50 of $279 \mathrm{~kb}$. De novo assembly (using GRCh37 and GRCh38) and variant annotation were performed using Bionano Solve version 3.4, which includes two separate algorithms for SV and CNV detection. Annotated variants were filtered for rare events as described previously (Mantere et al. 2021). In addition, the genomic region spanning the CEVA haplotype was analyzed visually in Bionano Access version 1.4.3.

\section{PacBio long-read sequencing}

Genomic DNA was isolated from peripheral blood according to standard procedures and subjected to long-read genome Hi-Fi sequencing using the SMRT sequencing technology (Pacific Biosciences, Menlo Park, CA, USA). Library preparation was performed using the SMRTbell ${ }^{\mathrm{TM}}$ Template Prep Kit 2.0 (Pacific Biosciences, Menlo Park, CA, USA) following the manufacturer's instructions. Size selection was performed using a BluePippin DNA size selection system (target fragments $\sim 15-18 \mathrm{~kb}$ ). Sequence primer V2 and polymerase 2.0 were used for binding. Subsequently, the SMRTbell library was loaded on an 8 M SMRTcell and sequencing was performed on a Sequel II system (Pacific Biosciences, Menlo Park, CA, USA). Circular consensus sequencing (CCS), Hi-Fi reads, were generated using the CCS (v4.2.0) tool and were aligned to the GRCh37/hg19 reference genome with pbmm2 (v.1.3.0). The unique molecular yield was $93.46 \mathrm{~Gb}$ and the post-alignment $\mathrm{Hi}-\mathrm{Fi}$ - coverage was 12× [Mosdepth v0.3.1, (Pedersen and Quinlan 2018)]. SV calling was performed using PBSV (v2.4.0) and annotation was applied using an in-house $\mathrm{SV}$ annotation pipeline.

\section{Results}

\section{Patient inclusion and genetic prescreening}

In this study, we included 28 Dutch index cases diagnosed with a unilateral or bilateral EVA and unilateral or bilateral HL. All individuals were prescreened for pathogenic variants in SLC26A4 (NM_000441.1) in a diagnostic setting and complete coverage of the coding and splice site ( \pm 14 nucleotides) regions of SLC26A4 was confirmed. In 16 individuals, a heterozygous (likely) pathogenic SLC26A4 variant was reported and these cases were deemed M1. In the remaining 12 individuals, no potentially pathogenic variants were found in the coding or splice site regions of this gene, and these subjects were therefore considered M0. Causative variants in other genes associated with arHL (Van Camp and Smith 2021) were addressed and excluded by analyzing available sequencing data (WES or MIPs-based) or in WGS data obtained in this study (Online Resource Table S2). This revealed no homozygous or compound heterozygous variants that were known or predicted to be pathogenic, except two compound heterozygous variants in OTOGL (NM_173591.3) in individual SLC012 (Online Resource Table S4). The c.890C > T (p.(Pro297Leu)) variant in $O T O G L$ has, however, been reported as (likely) benign in ClinVar (Landrum et al. 2018) and the Deafness Variation Database (Azaiez et al. 2018) and is classified as likely benign according to the ACMG guidelines (Oza et al. 2018). The c. $1369 \mathrm{G}>\mathrm{T}$ [p.(Val457Leu)] is considered as a variant of unknown significance (ACMG classification). Furthermore, subject SLC012 has progressive high-frequency HL, which differs from the symmetric, moderate, and stable HL associated with OTOGL (DFNB84B) (Oonk et al. 2014; Yariz et al. 2012). Therefore, we considered the identified OTOGL variants as non-causative. For none of the cases, (likely) pathogenic variants (UV4/UV5, ClinVar) were identified in genes associated with autosomal dominant HL or syndromic HL (Van Camp and Smith 2021).

\section{The CEVA haplotype is enriched in Dutch monoallelic SLC26A4 cases}

In 2017, Chatteraj et al. described the $\geq 613$-kb CEVA haplotype located centromeric of the SLC26A4 gene to be enriched in M1 SLC26A4 cases and M0 cases with HL and EVA (Chattaraj et al. 2017). To investigate whether this haplotype is also enriched in the selected Dutch cohort of M0 and M1 SLC26A4 cases, we screened for the presence of this haplotype using VNTR marker analysis followed by Sanger sequencing of the 12 CEVA-associated SNPs. The CEVA haplotype was detected in 8 out of $16(50 \%)$ M1 individuals and 2 out of 12 (16.7\%) M0 subjects (Fig. 1, Table 1). In two additional M1 individuals (SLC040 and SLC071), only a partial CEVA haplotype was found, harboring 9/12 SNPs. We will refer to this smaller haplotype as the variant 1-CEVA (V1-CEVA) haplotype.

The CEVA haplotype has an AF of $2.8 \%$ in the $1000 \mathrm{G}$ database (28 in 1006 alleles) (Chattaraj et al. 2017; Genomes Project Consortium et al. 2015), and an AF of 3.3\% in an in-house control cohort consisting of 322 healthy unrelated individuals (21 in 644 unphased alleles). This implies a significant enrichment of the CEVA haplotype in our M1 cohort ( 8 in 32 alleles) compared to the $1000 \mathrm{G}$ database ( $p$ value $5.419^{*} 10^{-6}$ ) and the control cohort ( $p$ value $2.187^{*} 10^{-5}$ ) as determined by a two-sided Fisher's exact test). The two M1 


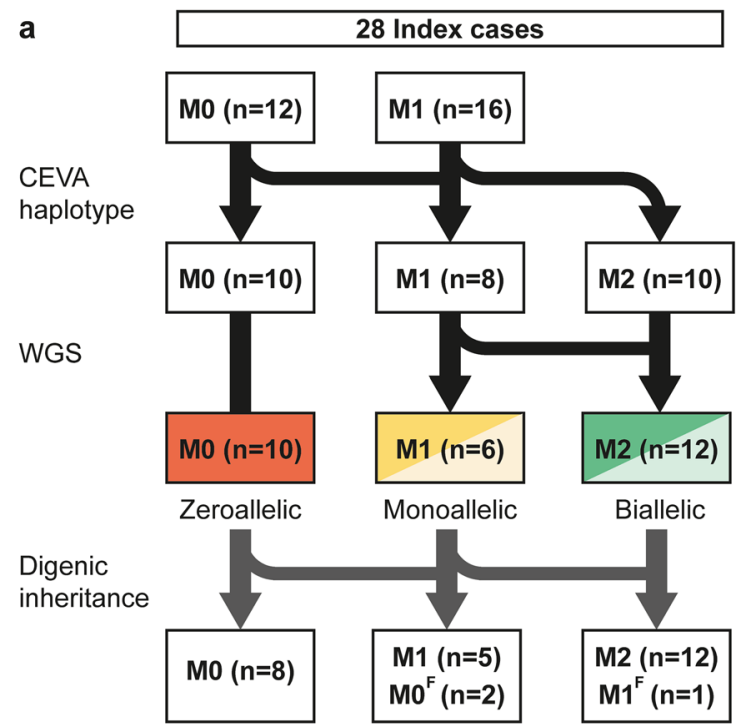

Fig. 1 Overview of genetic analyses performed in zeroallelic and monoallelic SLC26A4 cases. a, b To explain the missing heritability in zeroallelic (M0, $n=12$ ) and monoallelic (M1, $n=16)$ SLC26A4 cases, different genetic analyses were performed. First, individuals were screened for the presence of the CEVA haplotype (M0/CEVA, $n=2$; M1/CEVA, $n=10$ ). Second, whole-genome sequencing (WGS) was performed in all monoallelic cases (M0/CEVA, M1) to identify

cases with the V1-CEVA haplotype were not included in this statistical analysis. Also this V1-CEVA allele is significantly enriched in our M1 cohort as only a single V1-CEVA allele is reported in the $1000 \mathrm{G}$ database (1 in 1006 alleles) (Chattaraj et al. 2017) (p-value 0.0027). The CEVA haplotype was not found to be significantly enriched in the M0 cohort ( 2 in 24 alleles). Although the pathogenicity of the CEVA haplotype is unclear, the significant enrichment of the haplotype within this M1 patient cohort and the patient cohorts (M1 and M0) previously described by Chattaraj and co-workers strongly suggests that a pathogenic defect resides within this haplotype (Chattaraj et al. 2017). Because of this strong association of the CEVA haplotype with HL and EVA, we considered the M1 individuals carrying the CEVA or the V1-CEVA haplotype as genetically explained (M1/CEVA), and M0 individuals with the CEVA haplotype (M0/CEVA) as monoallelic in further steps of this study. For six M1 individuals, it could not be conclusively determined whether the CEVA haplotype was present in trans with the pathogenic SLC26A4 variant, as the genetic material of family members was not available (Table 1).

\section{Whole-genome sequencing reveals potential SLC26A4 splice and regulatory variants in M1 subjects without the CEVA haplotype}

To detect any potentially missed coding or unidentified intronic SLC26A4 variants or variants located in cis

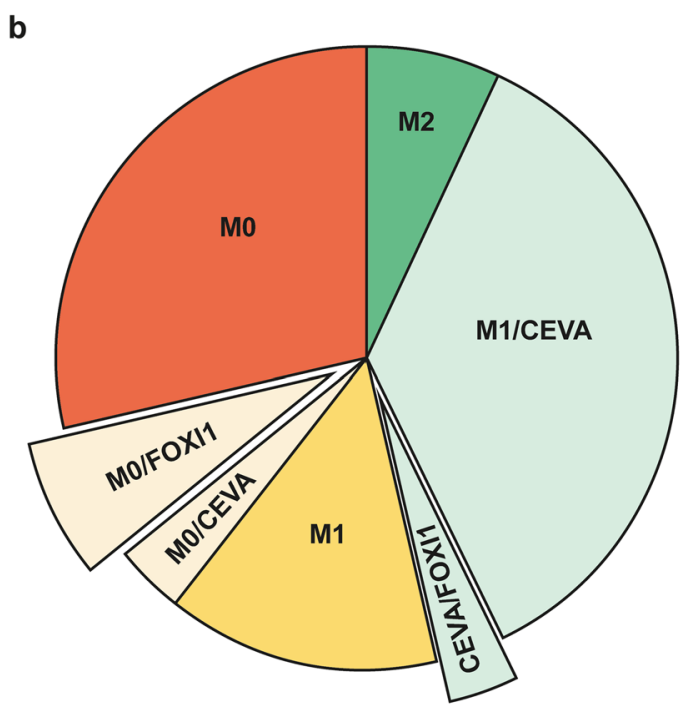

potential structural, splice (M2, $n=2)$ or regulatory variants. Finally, sequencing data were screened for potentially pathogenic variants in the EPHA2, FOXI1 and KCNJ10 genes. Digenic inheritance has been previously suggested for variants in these genes and the SLC26A4 gene. In three cases (M0/FOXI1 $\left(\mathrm{M}^{\mathrm{F}}\right), n=2$, CEVA/FOXI1 $\left(\mathrm{M} 1^{\mathrm{F}}\right)$, $n=1$ ), a potentially pathogenic variant in FOXI1 (NM_012188.4, c. $677 \mathrm{C}>\mathrm{T}$ ) was identified

regulatory elements of the gene, WGS analysis was performed for all six M1 individuals who could not be genetically explained by the presence of the CEVA haplotype. Additionally, WGS analysis was performed for the two M0/ CEVA individuals. In none of these eight cases, SVs overlapping with the SLC26A4 gene were identified by WGS.

To identify any variants with a potential effect on splicing, the deep-learning algorithm SpliceAI was employed (Jaganathan et al. 2019). In two M1 individuals (SLC048 and SLC085), a rare heterozygous potentially splice altering SLC26A4 variant was identified (Table 2). For both variants, the predicted splice defect was investigated using an in vitro splice assay performed in HEK293T cells. For SLC048, a canonical splice site variant (c.1342-2A > C), that was overlooked during prescreening efforts, was predicted to remove the splice acceptor site. This variant was previously reported in a study performed by Van Beeck Calkoen and coworkers and in ClinVar (van Beeck Calkoen et al. 2019). Indeed, the splice assay revealed loss of the acceptor site and usage of an alternative splice acceptor site located thirteen nucleotides downstream (Online Resource Figure S1A). This leads to the formation of an out-of-frame exon 12 and premature protein truncation [p.(Ser448Leufs*3)]. Based on these results, the variant was classified as pathogenic according to the ACMG guidelines (Oza et al. 2018). In SLC085, a synonymous variant (c.471C $>\mathrm{T}$, classified as likely benign in ClinVar) was identified in exon 5. SpliceAI predicts that this variant strengthens an alternative splice acceptor site (27 
Table 1 Detection of the CEVA haplotype in $\mathrm{M} 1$ and $\mathrm{M} 0$ individuals

\begin{tabular}{|c|c|c|c|}
\hline \multirow[t]{2}{*}{ Case } & \multicolumn{2}{|l|}{ Allele 1} & \multirow{2}{*}{$\begin{array}{l}\text { Allele } 2 \\
\text { CEVA }\end{array}$} \\
\hline & Variant & ACMG & \\
\hline \multicolumn{4}{|c|}{ Zeroallelic SLC26A4 cases } \\
\hline SLC014 & c.2059G > T; p.(Asp687Tyr) & UV3 & \\
\hline SLC015 & - & - & \\
\hline SLC017 & - & - & \\
\hline SLC039 & - & - & ACACATG-GC-C (CEVA) \\
\hline SLC043 & - & - & \\
\hline SLC052 & - & - & \\
\hline SLC069 & - & - & \\
\hline SLC070 & - & - & \\
\hline SLC073 & - & - & \\
\hline SLC080 & - & - & ACACATG-GC-C (CEVA) \\
\hline SLC084 & - & - & \\
\hline SLC086 & - & - & \\
\hline \multicolumn{4}{|c|}{ Monoallelic $S L C 26 A 4$ cases } \\
\hline SLC002 & c.412G > T; p.(Val138Phe) & UV5 & \\
\hline SLC003 & c.131dup; p.(Thr45Aspfs*42) & UV5 & $\underline{\text { ACACATG-GC-C (CEVA) }}$ \\
\hline $\mathrm{SLC} 012^{\mathrm{a}}$ & c.707 T>C; p(Leu236Pro) & UV5 & ACACATG-GC-C (CEVA) \\
\hline SLC013 & c. $1001+1 \mathrm{G}>\mathrm{A} ;$ p. $(?)$ & UV5 & $\underline{\text { ACACATG-GC-C (CEVA) }}$ \\
\hline SLC018 & c.349C > T; p.(Leu117Phe) & UV5 & \\
\hline SLC031 & c. $1001+1 \mathrm{G}>\mathrm{A} ; \mathrm{p} .(?)$ & UV5 & $\underline{\text { ACACATG-GC-C (CEVA) }}$ \\
\hline SLC032 & c.1334 T> G; p.(Leu445Trp) & UV5 & \\
\hline SLC036 ${ }^{\mathrm{a}}$ & c.1246A > C; p.(Thr416Pro) & UV5 & $\underline{\text { ACACATG-GC-C }}$ (CEVA) \\
\hline SLC040a & c.655_656dup; p.(Phe223Alafs*15) & UV5 & GTTCATG-GC-C (V1-CEVA) \\
\hline SLC045 & c.1334 T> G; p.(Leu445Trp) & UV5 & \\
\hline SLC048 & c.706C > G; p.(Leu236Val) & UV4 & \\
\hline SLC056 & c.707 T > C; p(Leu236Pro) & UV5 & ACACATG-GC-C (CEVA) \\
\hline $\mathrm{SLC}_{071^{\mathrm{a}}}$ & c.1334 T> G; p.(Leu445Trp) & UV5 & GTTCATG-GC-C (V1-CEVA) \\
\hline SLC078 & c. $304 \mathrm{G}>$ C; p.(Gly102Arg) & UV4 & $\underline{\text { ACACATG-GC-C }}$ (CEVA) \\
\hline SLC079 & c. $1001+1 \mathrm{G}>\mathrm{A} ; \mathrm{p} .(?)$ & UV5 & ACACATG-GC-C (CEVA) \\
\hline SLC085 & c.706C > G; p.(Leu236Val) & UV4 & \\
\hline
\end{tabular}

Presence of the CEVA haplotype was tested in zeroallelic (M0) and monoallelic (M1) SLC26A4 cases with a unilateral or bilateral enlarged vestibular aqueduct. SLC26A4 (NM_000441.1) variants reported in ClinVar as (likely) pathogenic (UV4, UV5) were considered causative, whereas variants reported as (likely) benign or of unknown significance were considered non-causative. In ten individuals, the complete CEVA haplotype was detected (ACACATG-GC-C), whereas in two individuals a shorter version of the haplotype was found, consisting of 9/12 CEVA SNPs (GTTCATG-GC-C; V1). For individuals marked with an a , it could be conclusively determined that the (V1-)CEVA haplotype is present on the trans SLC26A4 allele

$A C M G$ variant classification according to the American College of Medical Genetics and Genomics (ACMG) classification guidelines (Oza et al. 2018), UV3 uncertain significance, UV4 likely pathogenic, UV5 pathogenic nucleotides downstream of the variant). Indeed, an in vitro splice assay confirmed that the alternative splice acceptor site is used, which leads to the partial deletion of exon 5 and a truncated protein [p.(Gly139Alafs*6)] (Online Resource Figure S1B). Therefore, this variant is now classified as pathogenic according to the ACMG classification guidelines (Oza et al. 2018). The observed splice defect resulting from this synonymous variant underlines the importance of evaluating potential splice effects of all rare variants in coding sequences, using in silico prediction splice tools. We considered the two identified splice variants as pathogenic and the HL of the two individuals as genetically explained, thus M2.

To explore variants that are potentially located within a cis-regulatory element of SLC26A4, we extracted all (predicted) human enhancer and promoter elements that are associated with the SLC26A4 gene from the GeneHancer (Fishilevich et al. 2017) and EnhancerAtlas (Gao and Qian 2020) databases (Online Resource Table S5). GeneHancer 

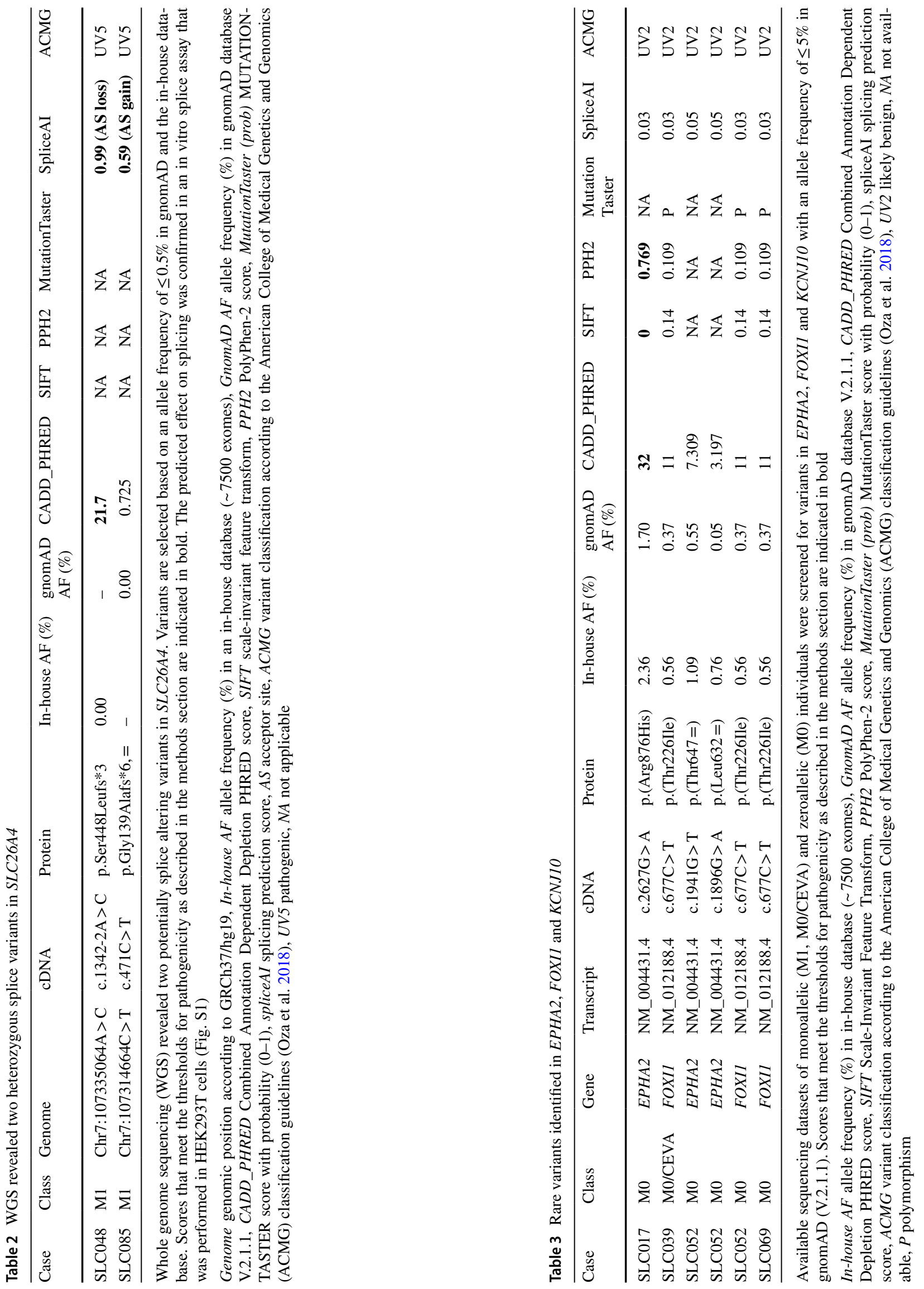
V5 is a collection of both predicted and experimentally validated enhancer-to-gene and promoter-to-gene interactions, based on information integrated from multiple resources: ENCODE (Dunham et al. 2012), Ensembl (Zerbino et al. 2015), FANTOM5 (Andersson et al. 2014), VISTA (Visel et al. 2007), dbSuper (Khan and Zhang 2016), EPDnew (Dreos et al. 2013), UCNEbase (Dimitrieva and Bucher 2013) and CraniofacialAtlas (Wilderman et al. 2018). For each regulatory element, a gene interaction score $(>7)$ and element confidence score $(>0.7)$ are provided. The EnhancerAtlas V2 is a database providing enhancer annotations in different species based on experimental datasets determined in several tissues and cell types.

WGS data were analyzed for variants located within these elements and two rare potentially regulatory variants (Chr7:107220628C > A, Chr7:107384987C > G) were identified in two M1 individuals (SLC002 and SLC045) (Online Resource Table S6). Both variants are located in a predicted enhancer element of SLC26A4 according to GeneHancer. We did not find any strong indication of a functional effect for the two variants based on (nucleotide) conservation scores [PhyloP, UCSC genome browser (Kent et al. 2002)) or loss of transcription factor binding sites [JASPAR database (Fornes et al. 2020)]. Therefore, the variants were considered non-pathogenic, although only a reporter assay can completely exclude a potential regulatory effect of the variants on SLC26A4 expression.

\section{A FOXI1 missense variant is revealed in three unrelated index cases}

Several studies have suggested a potential digenic inheritance for SLC26A4 variants and variants in KCNJ10 and FOXII (Pique et al. 2014; Yang et al. 2009, 2007). Additionally, a more recent study suggested digenic inheritance with pathogenic variants in EPHA2 ( $\mathrm{Li}$ et al. 2020). We screened all remaining genetically unexplained individuals (M1, M0/ CEVA and M0) for variants in these genes with an $\mathrm{AF} \leq 5 \%$ (gnomAD V2.1.1). In cases for which only MIP sequencing data was available, coding regions and exon-intron boundaries of FOXII and the regions harboring the reported pathogenic variants in EPHA2 (c.1063G > A; p.(G355R), c.1532C > T; (p.T511M), NM004431.4) were analyzed using Sanger sequencing. In three individuals (SLC039; M0/CEVA, SLC052; M0 and SLC069; M0) a c.677C > T (p.(Thr226Ile)) FOXI1 (NM_012188.4) missense variant was identified (Table 3). The variant was not identified in any of the M1/CEVA or the two M2 cases. FOXII encodes the Forkhead transcription factor FOXI1, a key transcriptional regulator of SLC26A4 (Yang et al. 2007). Segregation analysis has confirmed that the FOXII variant is not co-inherited with the CEVA allele in individual SLC039, which is in line with digenic inheritance. The Thr226 residue is located outside of the conserved forkhead DNA-binding domain of FOXI1 (amino acids 94-211) (Yang et al. 2007) and none of the in silico tools used for analysis predicted a deleterious effect of the c.677C $>$ T variant. Nevertheless, the variant is enriched in individuals diagnosed with $\mathrm{HL}$ and EVA ( 3 in 56 alleles in the study cohort versus 165 in 26.590 alleles of the in-house WES cohort, $p$ value 0.0004 ), and we consider the c.677C $>$ T FOXII variant as an interesting candidate for functional validation.

In case SLC017, a heterozygous missense variant in EPHA2 was detected (c.2627G > A) [p.(Arg876His)]. Although the variant is predicted to be pathogenic by in silico prediction tools, it has a relatively high $\mathrm{AF}$ of $1.70 \%$ (gnomAD) and 2.36\% (in-house database) and is classified as likely benign according to the ACMG classification guidelines. Because the variant was only found in an M0 $S L C 26 A 4$ case, a potential digenic inheritance of pathogenic $S L C 26 A 4$ variants and the newly identified EPHA2 variant could not be addressed.

To summarize, the CEVA haplotype or a short CEVA haplotype (V1-CEVA) was detected in 12 of the 28 index cases $(16 \mathrm{M} 1,12 \mathrm{M} 0)$ that were included in our study (Fig. 1). In two individuals (M1), an SLC26A4 splice variant was identified using WGS. After performing these genetic analyses by which the enrichment of the (V1-)CEVA haplotype in M1 cases was demonstrated, we consider the HL in 12 individuals to be associated with $S L C 26 A 4$ defects and these subjects to be genetically explained (2 M2, $10 \mathrm{M} 1 /$ CEVA), six individuals are considered M1 (4 M1, 2 M0/ CEVA), and ten individuals are still considered M0. Additionally, in three individuals ( $1 \mathrm{M} 0 / \mathrm{CEVA}, 2 \mathrm{M} 0$ ) a potentially pathogenic variant in FOXII was found.

\section{Determination of boundaries of the CEVA haplotype}

To identify the true pathogenic defect located on the CEVA haplotype, an in-depth analysis of this genomic region was performed. Firstly, the exact boundaries of the genomic region shared by CEVA haplotype carriers were determined using VNTR marker analysis. For two individuals with the complete CEVA haplotype and the two subjects with the V1-CEVA haplotype, DNA samples of family members were available, allowing reliable determination of the marker alleles located within the haplotype. A shared haplotype of $0.89 \mathrm{Mb}$ delimited by markers D7S501 and D7S2459 was identified (Fig. 2 and Online Resource Figure S2). Although the V1-CEVA haplotype shares the marker alleles with the complete CEVA haplotype, the absence of SNPs 1-3 potentially delimits the shared haplotype even more $(0.57 \mathrm{Mb}$, CEVA SNP 3-D7S2459). The remaining eight individuals with the complete CEVA haplotype share identical marker alleles in the $0.89 \mathrm{Mb}$-sized region, although they could not be conclusively assigned to the haplotype as no segregation 
a

\begin{tabular}{|c|c|c|c|c|c|c|c|c|c|c|c|c|c|}
\hline Marker & $\mathrm{Mb}$ & 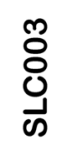 & 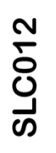 & $\begin{array}{l}\text { D్ } \\
\text { ๘ }\end{array}$ & 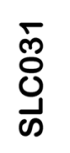 & 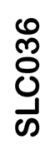 & 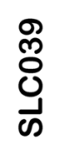 & 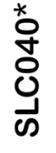 & $\begin{array}{l}0 \\
\text { ઠొ } \\
0 \\
\text { ம }\end{array}$ & 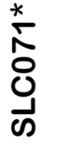 & 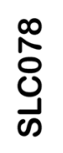 & 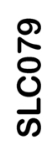 & $\begin{array}{l}\text { \& } \\
\text { ర } \\
\text { ம }\end{array}$ \\
\hline D7S501 & 106.44 & (1) & 1 & (7) & 3 & 1 & \begin{tabular}{|l|}
$(5)$ \\
\end{tabular} & 7 & \begin{tabular}{|l|}
$(7)$ \\
\end{tabular} & 7 & 7 & $(7)$ & $(7)$ \\
\hline D7S2420 & 106.89 & 5 & 7 & (7) & (7) & 7 & (7) & 7 & \begin{tabular}{|l}
7 \\
\end{tabular} & 7 & (7) & (7) & (7) \\
\hline SNP8 & 106.99 & (1) & 1 & (1) & (1) & 1 & (1) & 1 & (1) & 1 & (1) & (1) & (1) \\
\hline D7S496 & 107.15 & \begin{tabular}{|l|}
$(4)$ \\
\end{tabular} & 4 & (4) & (4) & 4 & (4) & 4 & (4) & 4 & (4) & (4) & $(4)$ \\
\hline SNP11 & 107.24 & (1) & 1 & (1) & (1) & 1 & (1) & 1 & (1) & 1 & (1) & (1) & $(1)$ \\
\hline D7S2459 & 107.33 & 5 & 3 & 5 & 5 & 5 & (5) & 4 & 4 & 5 & (5) & (3) & $(5)$ \\
\hline
\end{tabular}

b
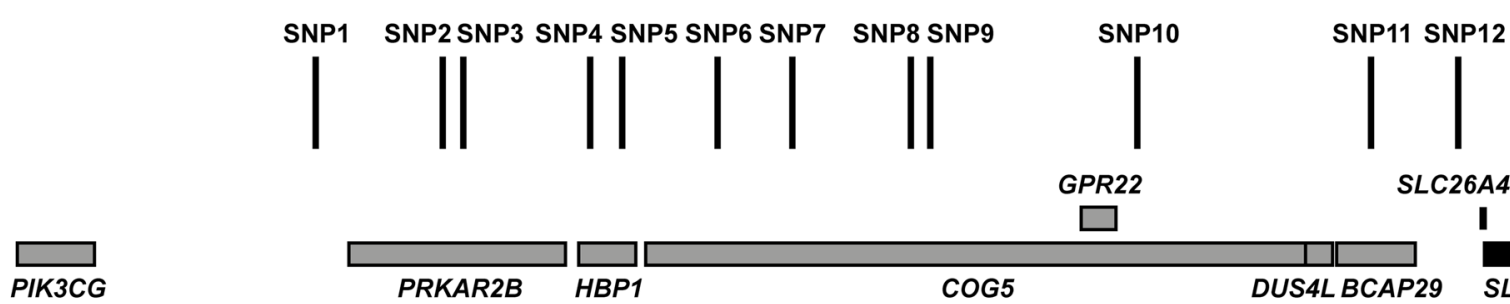

PRKAR2B

HBP1

COG5

SLC26A4-AS1

I

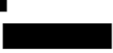

SLC26A4

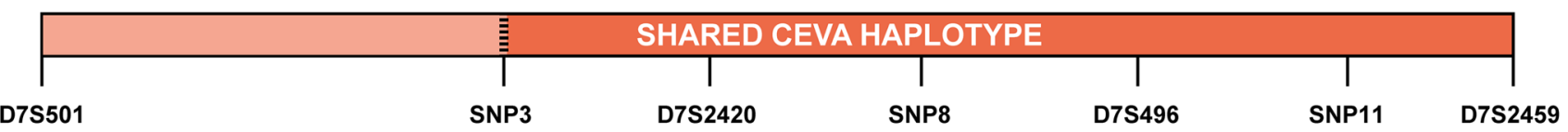

Fig. 2 Determination of the boundaries of the shared CEVA haplotype. a The CEVA haplotype was detected in 10 individuals, in an additional 2 individuals (SLC040 and SLC071, indicated with *), a smaller haplotype was found, termed V1-CEVA. To determine the boundaries of the CEVA haplotype, VNTR marker analysis was performed. The shared haplotype (0.89 Mb, CEVA; 0.57 Mb V1-CEVA is marked in orange. For marker D7S2420 (light-orange) a deviating CA-repeat length was determined in SLC003. Nevertheless, the marker is still considered to be potentially part of the shared haplotype as a change or repeat length cannot be excluded. Genomic posi-

analysis could be performed. For individual SLC003, a deviating repeat length was identified for marker D7S2420. As we cannot exclude a rare event to be responsible for the change in allele length, this marker was still considered part of the shared CEVA haplotype.

\section{Short-read WGS did not reveal a pathogenic defect on the CEVA haplotype}

Because of the significant enrichment of the CEVA haplotype in M1 cases, we hypothesized that the subjects with the CEVA haplotype share a yet elusive pathogenic defect. To identify this defect on the CEVA haplotype, short-read WGS was performed in two individuals (SLC012 and SLC036) carrying the CEVA haplotype in trans with a pathogenic variant in SLC26A4 (M1/CEVA). All heterozygous variants with an $\mathrm{AF} \leq 5 \%$ in gnomAD that were shared between the two individuals and located within the determined boundaries of the CEVA haplotype were analyzed (Online Resource Table S7). In total, 20 shared variants remained and included the 12 original SNPs that previously defined the CEVA tions $(\mathrm{Mb})$ are according to the UCSC Genome Browser (GRCh37/ hg19). b A schematic overview of the identified shared CEVA haplotype (D7S501-D7S2459). Positions of the CEVA-associated SNPs and the genes located within the haplotype region (CEVA, D7S501D7S2459; V1-CEVA, SNP3-D7S2459) have been indicated. All SNPs are located within intronic or intergenic regions. Genomic positions of the CEVA-associated SNPs are provided in Table S7. SLC26A4 (NM_000441.1) is only partially included (exons 10/21) in the shared haplotype

haplotype (Chattaraj et al. 2017). Sixteen of the shared variants are located in intronic regions, but for none of them, a significant effect (score $\geq 0.1$ ) on splicing is predicted by SpliceAI. Two variants are located within a cis-regulatory element of SLC26A4 according to the GeneHancer database, however, these also show overlap with a long interspersed nuclear element (LINE) repeat element. One variant (CEVA SNP9) has a high nucleotide evolutionary conservation score (PhyloP, 2.769 [range - 14, 3]). No SVs or CNVs were detected within or overlapping with the CEVA haplotype and shared by the two individuals.

Regions harboring heterozygous variants with an $\mathrm{AF} \leq 5 \%$ in gnomAD that were not shared between SLC012 and SLC036 had sufficient coverage to exclude that these variants were only called in one of the subjects but present in both of them. None of the variants identified in either SLC012 or SLC036 were within the SLC26A4 gene or were obviously deleterious. SVs and CNVs within the CEVA boundaries were analyzed separately for the two subjects which did not reveal any of such variants that were not shared by the two studied subjects. To fully exclude that the 
CEVA haplotype harbors different pathogenic variants in the studied individuals, a study design including short- and long-read WGS in several nuclear families has to be applied.

\section{Optical genome mapping \& long-read sequencing}

To investigate the possibility that SVs were missed using short-read sequencing, optical genome mapping (Bionano Genomics) was performed using ultra-high molecular weight DNA isolated from peripheral blood cells of individual SLC012 (M1/CEVA). Optical genome mapping identified a total of $6,565 \mathrm{SVs}$, of which none were within the CEVA region (D7S501-D7S2459; chr7:106,440,266-107,360,254). Two SV calls (both calling the same 2196 bp insertion between chr7:107,367,549 and 107,373,585) were located just outside this region (Online Resource Figure S3A). This insertion was also called in $100 \%$ of our current optical genome mapping control cohort (Levy-Sakin et al. 2019), strongly suggesting that this reflects a reference problem rather than a real SV. Additionally, there were $22 \mathrm{CNV}$ calls, of which none were within the CEVA region.

Subsequently, PacBio long-read sequencing was performed on genomic DNA isolated from individual SLC079 (M1/CEVA; in trans status unknown). SV analysis of the long-read sequencing data revealed a total of 55,205 SVs, of which 12 within the CEVA region. After careful interrogation of the SVs, all of them were considered false positives based on SV length, and the presence of the SVs in an in-house control dataset. The CEVA haplotype region was also manually inspected in the IGV software, which did not reveal any indications for potential SVs (Online Resource Figure S3B). Interestingly, the insertion event that was detected with optical genome mapping and located just outside the CEVA region was also present in the longread sequencing data (chr7:107,370,573, 1612 bp insertion). This insertion was also present in available in-house control sequencing data, supporting the hypothesis the variant concerns a reference problem and is not a true SV.

\section{A comparable severity of hearing loss in the M1/ CEVA and $M 2$ cohorts}

As the CEVA haplotype was reported to be associated with a less severe HL phenotype than variants in the protein-coding or splice site regions of SLC26A4 (Chao et al. 2019), we addressed genotype-phenotype correlations in our cohort. We were able to retrieve pure tone audiometry of all subjects except for SLC071; for this subject, complete audiometry from only one ear was available (Online Resource Figure S4). The original CT or MRI scans of subjects SLC018 and SLC032 could not be retrieved. However, written reports of the imaging were available. Data on thyroid gland function were not consistently available and were therefore not included in this study. We applied the methods of Chao et al. (2019) to compare the severity of HL between four subject groups (M0, M1, M1/CEVA, and M2 Fig. 3, Table 4) (Chao et al. 2019). The M1/CEVA group includes the M1/ V1-CEVA subjects. Bilateral EVA was present in 7 of 10 (70\%) M1/CEVA subjects, in all 4 M1 subjects without the CEVA haplotype, and 7 of 10 (70\%) M0 subjects without the CEVA haplotype. All $11 \mathrm{M} 2$ subjects (reference cohort, SLC048 and SLC085) had bilateral EVA. The median pure tone audiometry in the M2 group ( $85 \mathrm{~dB} \mathrm{HL}, n=20$ ) was not significantly different from that of the M1/CEVA group ( $84 \mathrm{~dB}$ HL, $n=16$ ) and the M1 group (79.5 dB HL, $n=8)$ ( $p$ values 0.8300 and 0.7142 , respectively, all adjusted for age). Also, no difference was observed between the M1/CEVA group and the M1 group $(p=0.8782)$. In contrast, when we compare the M2 and M1/CEVA groups with the M0 group, we observed significant differences in the severity of HL ( $p=0.0015$ and $p=0.0135$, respectively). When compared to Chao et al., subjects in our study displayed a similar degree of median HL in the M2 group (86.3 and $85 \mathrm{~dB}$ in Chao et al. 2019 and the present study, respectively), more severe $\mathrm{HL}$ in the M1/CEVA group (47.5 and $84 \mathrm{~dB}$, respectively) and less severe HL in the M0 group (54.4 and $42 \mathrm{~dB}$ HL, respectively). Slight age differences were seen between the groups presented in Chao et al. 2019 and those in the current study (Online Resource Table S8). Chao and co-workers did not report audiometric data for the M1 group without the CEVA haplotype in trans, presumably due to the small sample size. Overall, in contrast to the study by Chao et al. (2019), the present study showed that subjects with biallelic pathogenic variants in the coding regions and splice sites

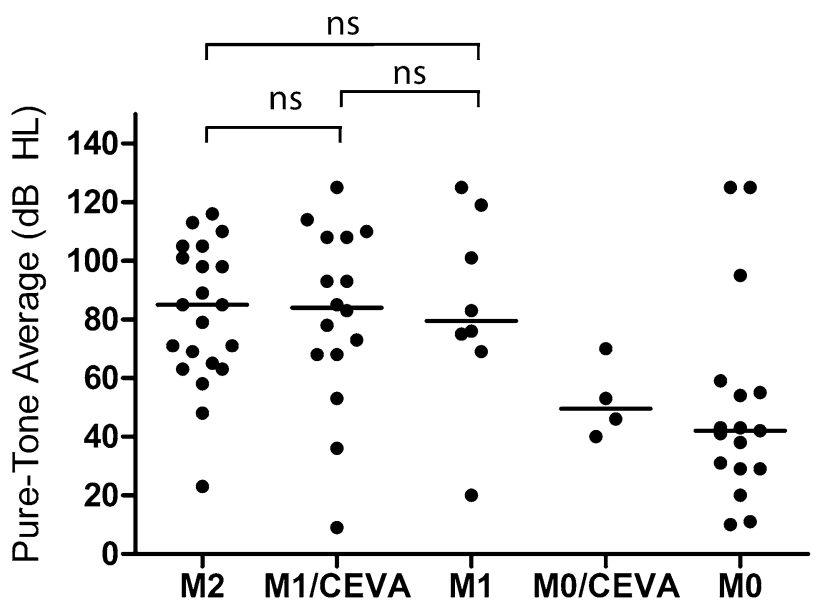

Fig. 3 Results of audiometric evaluation in affected individuals. PTA $_{0.5-4 \mathrm{kHz}}$ for ears with an EVA. Each dot represents the hearing level of an ear with an enlarged vestibular aqueduct, allocated to genotype class (M2, M1/CEVA, M1, M0/CEVA and M0). The M1/ CEVA group also includes subjects with an M1/V1-CEVA genotype. For an objective comparison, the same methods as used by Chao et al. (2019) were applied 


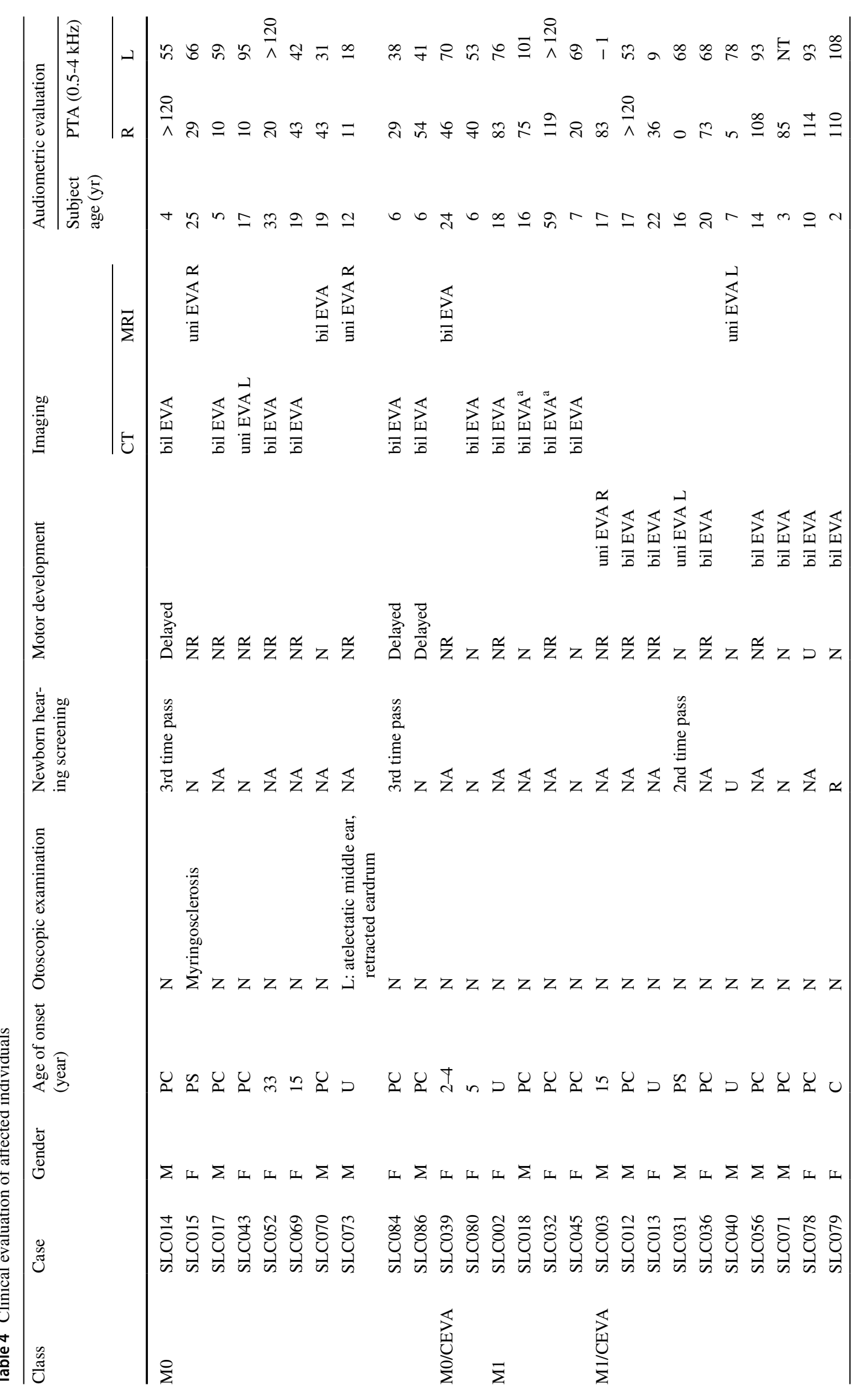




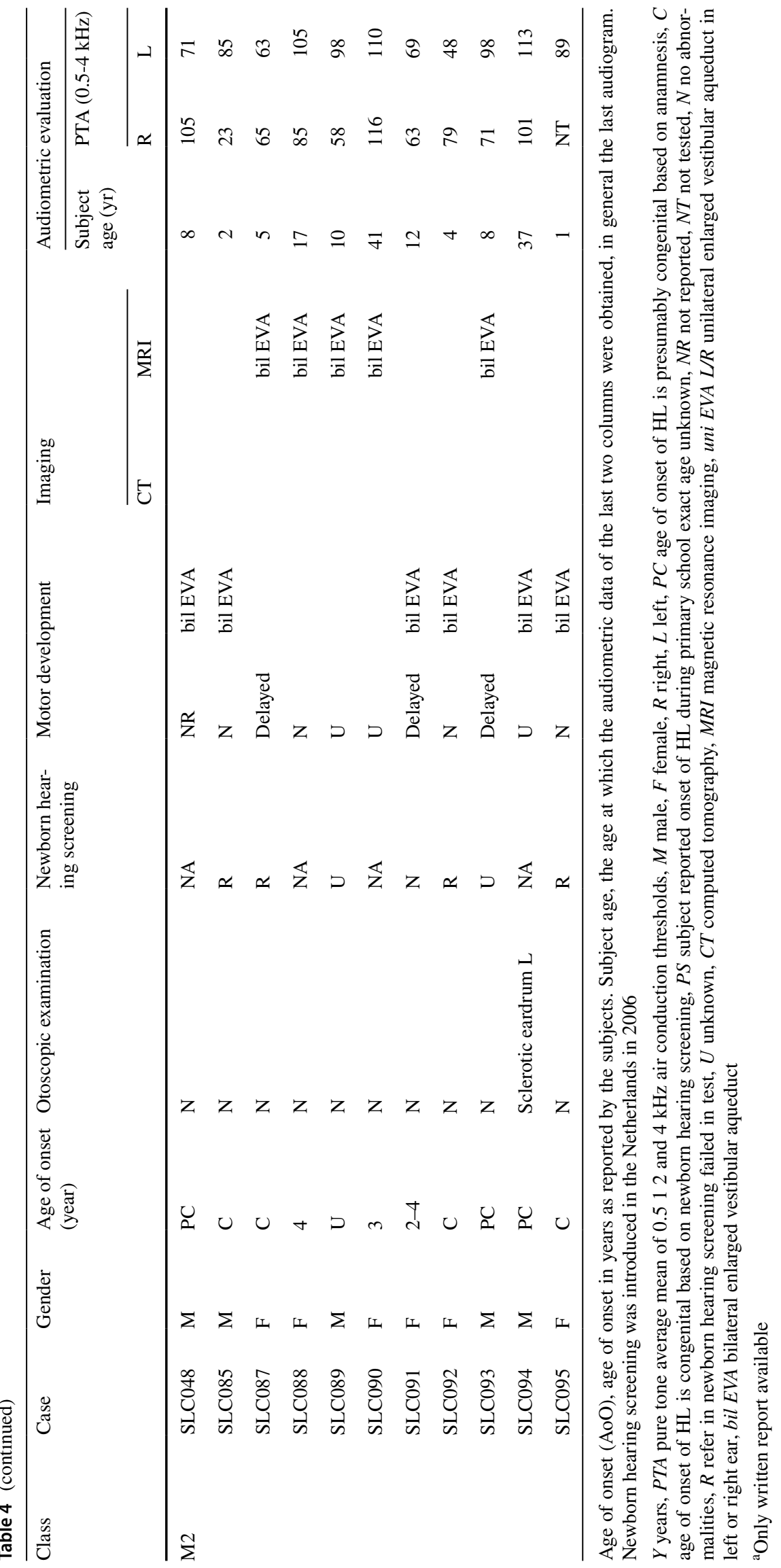


of SLC26A4 have a degree of HL that is similar to that of subjects with a monoallelic SLC26A4 variant and the CEVA haplotype. Due to the small sample size, we could not test the hypothesis that the CEVA haplotype acts as a modifier in M0 subjects as reported previously (Chao et al. 2019).

\section{Discussion}

In this study, we investigated 28 genetically unexplained Dutch index cases with HL and a unilateral or bilateral EVA. To elucidate the missing heritability in monoallelic SLC26A4 cases, who represent 14-31\% of subjects with HL and EVA (Azaiez et al. 2007; Mey et al. 2019), extensive genomic analyses as well as phenotyping were performed. Important findings in this study were (1) the enrichment of a shared (V1-)CEVA haplotype in M1 SLC26A4 cases, (2) two SLC26A4 splice variants and (3) the identification of a FOXI1 variant in three subjects suggesting a contribution of this variant to the etiology of HL and EVA. Furthermore, the genotype-phenotype analyses revealed that the severity of the HL associated with biallelic variants (M2) in SLC26A4 is comparable to the HL associated with a monoallelic variant in SLC26A4 with or without the CEVA haplotype (M1 and M1/CEVA).

For six M1 individuals, it could not be conclusively determined whether the CEVA haplotype was present in trans with the (likely) pathogenic SLC26A4 variant, as no genetic material of family members could be obtained. However, we anticipated that most if not all of the six M1 cases carry the CEVA haplotype in trans with the SLC26A4 variants because it seems highly unlikely that the SLC26A4 variants all have occurred on an allele with a frequency of $<3 \%$ in the population (Chattaraj et al. 2017). Furthermore, the cooccurrence of two partial CEVA haplotypes that together exactly mimic a heterozygous CEVA haplotype in 6 of 16 individuals is highly unlikely as the frequencies of partial CEVA haplotypes in the European population are all (far) below 1\% (Chattaraj et al. 2017). The same holds true for the two M0/CEVA cases for whom we could not determine the phase of the 12 SNPs in the CEVA haplotype.

In two cases, the V1-CEVA haplotype was identified. This smaller CEVA haplotype was also reported previously in a single M1 case by Chattaraj and coworkers and likely refines the CEVA haplotype. Alternatively, the V1-CEVA haplotype harbors a different genetic defect. The shared VNTR marker alleles of the V1-CEVA and the CEVA haplotype suggest that V1-CEVA refines the boundaries of the shared genomic region to $0.57 \mathrm{Mb}$.

We anticipated that a pathogenic variant co-segregates with the CEVA haplotype. Therefore, we subjected the shared genomic region to extensive genomic analyses that included WES, short- and long-read WGS, and optical genome mapping, to reveal any potential variants missed or misinterpreted in earlier studies. None of the applied sequencing or imaging techniques revealed rare SVs that overlap or are present within the CEVA haplotype. In the light of the proven accuracy and efficacy of especially optical genome mapping and long-read sequencing in SV detection (Chaisson et al. 2019), we deem it unlikely that any SVs within the CEVA region escaped detection. Additionally, we evaluated all SNVs with an $\mathrm{AF} \leq 5 \%$ (gnomAD) present within the region for predicted regulatory or splice altering effects but for none of the $20 \mathrm{SNV}$ s a potential effect was predicted by SpliceAI. Two SNVs overlap with a potential regulatory element of SLC26A4 (GeneHancer, EnhancerAtlas), and one variant is present within the intronic regions of this gene. However, all three variants are located within a highly repetitive element (LINE). Although little is known about the effects of genetic variation within LINE elements, a potential effect on the methylation landscape and consequently gene expression levels has been suggested (Xie et al. 2009) and such an effect can therefore not be excluded for the three indicated variants. For the remaining SNVs, no potential effects on transcript splicing or gene regulation were predicted. Nevertheless, we cannot rule out combinatory effects of the SNVs, since they are all located in cis. A thorough experimental (multi-omic) analysis is required to optimally assess the effects of the identified variants. RNA studies can be performed to detect quantitative or qualitative changes affecting the SLC26A4 transcripts. A defect observed on the RNA level could provide valuable insights that may point towards the true pathogenic defect, and prioritize one, or a combination, of the variants on the CEVA allele. However, SLC26A4 is not or at extremely low levels expressed in readily accessible patient cell types (e.g., fibroblasts and blood cells). The same holds true for induced pluripotent stem cells or otic progenitor cells (Hosoya et al. 2017). However, Hosoya and co-workers have successfully developed a protocol that allows the differentiation of otic progenitor cells into outer sulcus-like cells that express SLC26A4 at high levels. This protocol could potentially be a powerful tool to evaluate the consequences of CEVA haplotype at the RNA level.

$S L C 26 A 4$ is not the only gene present within the CEVA haplotype, which also spans BCAP29, COG5, DUS4L, $H B P 1, P I K 3 C G$, and PRKAR2B. For none of these genes, pathogenic variants associated with (syndromic) HL have been reported, nor has a function in the inner ear been described. The majority of the CEVA-associated SNVs $(16 / 20)$ are located within an intronic region of these genes, however, for none of these variants a splice altering effect is predicted by SpliceAI.

Since the genetic defect on the CEVA haplotype could not be pinpointed by the genetic analyses, we could not determine whether the AF of the defect is lower than that 
of the CEVA haplotype and more in line with the expected frequency based on the prevalence of HL (1:1,000 newborns (Morton and Nance 2006)) and the genetic heterogeneity of the condition. Alternatively, the CEVA haplotype could be considered a hypomorphic allele, of which the penetrance depends on the contribution of other co-existing (common) variants.

Not all M0 or M1 SLC26A4 cases could be genetically explained by the presence of the CEVA haplotype. Therefore, digenic inheritance with variants in EPHA2, FOXII, and $K C N 1 O$ was also explored as a potential explanation for the missing heritability. Digenic inheritance of defects in SLC26A4 and EPHA2 has recently been reported in two Japanese Pendred syndrome cases (Li et al. 2020). A c. $1063 \mathrm{G}>\mathrm{A}$ [p.(Gly355Arg)] and a c. $1532 \mathrm{C}>\mathrm{T}$ [p.(Thr511Met)] variant in EPHA2 were each found 'in trans' with a reported pathogenic variant in SLC26A4 (Deafness Variation Database (Azaiez et al. 2018)). EPHA2 was identified as a binding partner of pendrin, with a crucial role in regulating pendrin localization ( $\mathrm{Li}$ et al. 2020). The identified variants in EPHA2 were predicted to be pathogenic by several in silico predictions tools. However, the c. $1532 \mathrm{C}>\mathrm{T}$ variant has a relatively high allele frequency of $3.03 \%$ in the East Asian population, including 11 homozygotes (gnomAD). Yet, in the present study, we did not obtain indications for the digenic inheritance of variants in SLC26A4 and EPHA2 in subjects with HL and EVA. Besides for $E P H A 2$, a digenic mechanism has also been reported and debated for variants in SLC26A4 and KCNJ10 or FOXI1, with currently no consensus (Jonard et al. 2010; Landa et al. 2013; Pique et al. 2014; Yang et al. 2009, 2007). FOXI1 is a transcriptional regulator of SLC26A4 (Yang et al. 2007). We identified a c.677C $>\mathrm{T}$ (p.(Thr226Ile)) FOXI1 variant in three subjects (2 M0/FOXI1 and $1 \mathrm{M} 0 / \mathrm{CEVA} / F O X I 1)$. This variant was previously detected in an individual diagnosed with Pendred syndrome and a monoallelic pathogenic SLC26A4 variant (Pique et al. 2014). The variant has an allele frequency of $0.71 \%$ in non-Finnish Europeans (gno$\mathrm{mAD}$ ) and affects an amino acid residue located outside the DNA-binding domain but close to the nuclear localization signal (NucPred (Brameier et al. 2007)). Previously reported pathogenic FOXI1 variants have been shown to affect the DNA-binding properties of the protein (Enerbäck et al. 2018). We speculate that a variant affecting the localization motif of the protein could potentially have a loss of function effect as well. Although the variant is classified as likely benign according to the ACMG classification guidelines, we identified the variant three times in our cohort of genetically unexplained SLC26A4 cases and combined with the fact that it has been reported in a previous study (Pique et al. 2014), this suggests that the variant might actually contribute to the etiology of HL and EVA although not in a monogenic pattern. Interestingly, in $\mathrm{Foxil}^{-/-}$mice, the expansion of the endolymphatic compartment and an audio-vestibular phenotype was observed (Hulander et al. 2003). In situ hybridization of the endolymphatic duct and sac of these mice revealed complete absence of Slc26a4 mRNA expression. Functional studies, among which cellular localizations assays, are warranted to evaluate the effect of the c.677C $>$ T FOXI1 variant. We did not identify likely pathogenic variants in $K C N J 10(\mathrm{AF} \leq 5 \%)$ in our cohort.

WGS did not reveal strong candidate regulatory variants based on data derived from enhancer databases and transcription factor binding site predictions. Nevertheless, interpretation of regulatory variants is still considered complex and is limited by the lack of available epigenetic datasets for the inner ear. In addition, no SVs overlapping with SLC26A4 were detected using WGS, suggesting a limited contribution of SVs to the mutational landscape of SLC26A4. This is in line with earlier observations described in literature (Liu et al. 2021; Pique et al. 2014). For the monoallelic cases (M1, M0/CEVA), no long-read sequencing or optical genome mapping was performed. As it is generally accepted that most SVs could not be accurately detected using shortread sequencing approaches only (Chaisson et al. 2019), it cannot be excluded that causative SVs are present but missed due to technical limitations.

The present study did not confirm that the CEVA allele is associated with a milder HL compared to SLC26A4 variants affecting the protein-coding sequences, as indicated by Chao et al. (Chao et al. 2019). They discerned a significantly milder HL in their cohort of M1/CEVA subjects $(n=20$ ears, median $47.5 \mathrm{~dB}$ HL) than we have seen in our cohort of M1/ CEVA subjects ( $n=16$ ears, median $84 \mathrm{~dB}$ HL). A possible explanation for this discrepancy could be the progression of HL combined with a $\sim 5$-year difference in average age between the cohorts (7.5 and 12.8 years, respectively). Progression of $\mathrm{HL}$ is seen in up to $39.6 \%$ of EVA-ears (Alemi and Chan 2015), with progression rates of $\sim 3.5$ to $\sim 5.5 \mathrm{~dB} /$ year (Govaerts et al. 1999; Jackler and de la Cruz 1989). On the other hand, the older subjects in our M1/CEVA cohort show less severe HL than the younger subjects, which is questioning the relationship with age. Furthermore, there is also an average age difference of 5 years between the M2 groups in both studies (13.2 years and 18.4 years, respectively), while the severity of HL is comparable ( 85 and $86.3 \mathrm{~dB}$ HL, respectively).

The reported variability of the auditory phenotype associated with EVAs (Arjmand and Webber 2004; Gopen et al. 2011; Griffith and Wangemann 2011) may be another explanation for the observed differences in severity of $\mathrm{HL}$ in both studies. In literature, many prognostic factors such as genotype, EVA size and morphology, age, head trauma, and gender are reported as underlying explanations for this variability, although some of these studies draw contradicting conclusions (Alemi and Chan 2015; Archibald 
et al. 2019; Ascha et al. 2017; Gopen et al. 2011; Miyagawa et al. 2014; Rah et al. 2015; Saeed et al. 2021). In the same line, Song et al. reported intrafamilial differences in the severity of hearing loss in siblings with the same biallelic variants in SLC26A4 (Song et al. 2014). Larger sample sizes are needed to confirm or reject the hypothesis that the CEVA haplotype is associated with a milder HL phenotype.

The significant difference in HL severity between the $\mathrm{M} 2$ and M1/CEVA groups versus the M0 group suggests that SLC26A4 defects have a prognostic value which can be strengthened in the future by the identification of the underlying genetic defects in subjects of the M0 group.

In conclusion, the HL and EVA in 12 of the 28 studied subjects could be associated with $S L C 26 A 4$. In addition, we have identified genetic factors that might (partially) explain the phenotype in four additional subjects. However, we could not pinpoint the genetic defect that is present in the CEVA haplotype. The arrival of third-generation sequencing techniques, the expansion of epigenetic and transcriptomic datasets and the increasing understanding of non-coding, structural, and regulatory variants will aid in solving the missing heritability in SLC26A4 in the coming years. This is of great importance for counseling patients about the underlying cause and expected prognosis of their HL. Furthermore, as variants in SLC26A4 are a frequent cause of HL (Sloan-Heggen et al. 2016), it is an interesting target for the development of a genetic therapy (Kim et al. 2019). Although the involved molecular defect of the CEVA haplotype is still not resolved, the high prevalence of the CEVA haplotype suggests that a significant portion of monoallelic SLC26A4 cases can be associated with SLC26A4 defects by testing for the presence of this haplotype.

Supplementary Information The online version contains supplementary material available at https://doi.org/10.1007/s00439-021-02336-6.

Acknowledgements The authors thank Lieke Lamers, Jolinda Put and Evelien Verwoerd for their assistance in genetic analyses and Ronald van Beek, Ellen Kater-Baats, Marcel Nelen and Michiel Oorsprong for technical support. We would like to thank Mieke Wesdorp for including subjects in the study and Galuh D.N. Astuti and Christian Gilissen for their contribution to statistical and bioinformatic analyses. We thank the Radboudumc Genomics Technology Center, Radboud University Medical Center Nijmegen, for their technical assistance.

The DOOFNL consortium is a Dutch nationwide collaboration on hereditary hearing loss and consists of M.F. van Dooren, S.G. Kant, H.H.W. de Gier, E.H. Hoefsloot, M.P. van der Schroeff (ErasmusMC, Rotterdam, the Netherlands), L.J.C. Rotteveel, F.G. Ropers (LUMC, Leiden, the Netherlands), J.C.C. Widdershoven, J.R. Hof, E.K. Vanhoutte (MUMC+, Maastricht, the Netherlands), I. Feenstra, H. Kremer, C.P. Lanting, R.J.E. Pennings, H.G. Yntema (Radboudumc, Nijmegen, the Netherlands), R.H. Free and J.S. Klein Wassink-Ruiter (UMCG, Groningen, the Netherlands), R.J. Stokroos, A.L. Smit, M.J. van den Boogaard (UMC, Utrecht, the Netherlands) and F.A. Ebbens, S.M. Maas, A. Plomp, T.P.M. Goderie, P. Merkus and J. van de Kamp (Amsterdam UMC, Amsterdam, the Netherlands).
Author contributions JJS and SEdB co-designed the study and wrote the manuscript. JJS included subjects in the study and collected samples, performed subject evaluation and analyzed audiometric data, SEdB and JO conducted experiments and analyzed genetic sequencing data. CPL and SAHP analyzed audiometric and imaging data and revised the manuscript. $\mathrm{LO}, \mathrm{TM}, \mathrm{RD}, \mathrm{AH}$ and $\mathrm{KN}$ were involved in long-read sequencing and optical genome mapping, $\mathrm{LO}, \mathrm{AH}$ and $\mathrm{KN}$ revised the manuscript. EdV, FPMC and SR discussed the experimental design and critically read and revised the manuscript. HGY analyzed diagnostic WES data and revised the manuscript. RJEP co-designed and supervised the clinical part of the study, and revised the manuscript. HK co-designed the study, supervised the project and wrote the manuscript.

Funding This study was financially supported by a DCMN Radboudumc grant (to H.K. and F.P.M.C.) and by a grant of the HeinsiusHoubolt foundation (to R.J.E.P. and H.K). TM was supported by the Sigrid Jusélius Foundation. This research was part of the Netherlands $\mathrm{X}$-omics Initiative and partially funded by NWO (The Netherlands Organization for Scientific Research; project 184.034.019).

Availability of data and material Not applicable.

Code availability Not applicable.

\section{Declarations}

Conflict of interest The authors have no conflict of interest to declare.

Ethics approval This study was approved by the medical ethics committee of the Radboud University Medical Center (Registration No. NL33648.091.10) and was carried out according to the Declaration of Helsinki.

Consent to participate Written informed consent was obtained from all participants or their legal representatives.

Consent for publication Written informed consent was obtained from all participants or their legal representatives.

Open Access This article is licensed under a Creative Commons Attribution 4.0 International License, which permits use, sharing, adaptation, distribution and reproduction in any medium or format, as long as you give appropriate credit to the original author(s) and the source, provide a link to the Creative Commons licence, and indicate if changes were made. The images or other third party material in this article are included in the article's Creative Commons licence, unless indicated otherwise in a credit line to the material. If material is not included in the article's Creative Commons licence and your intended use is not permitted by statutory regulation or exceeds the permitted use, you will need to obtain permission directly from the copyright holder. To view a copy of this licence, visit http://creativecommons.org/licenses/by/4.0/.

\section{References}

Adzhubei IA, Schmidt S, Peshkin L, Ramensky VE, Gerasimova A, Bork P, Kondrashov AS, Sunyaev SR (2010) A method and server for predicting damaging missense mutations. Nat Methods 7:248249. https://doi.org/10.1038/nmeth0410-248 
Alemi AS, Chan DK (2015) Progressive hearing loss and head trauma in enlarged vestibular aqueduct: a systematic review and metaanalysis. Otolaryngol-Head Neck Surg 153:512-517. https://doi. org/10.1177/0194599815596343

Andersson R, Gebhard C, Miguel-Escalada I, Hoof I, Bornholdt J, Boyd M, Chen Y, Zhao X, Schmidl C, Suzuki T, Ntini E, Arner E, Valen E, Li K, Schwarzfischer L, Glatz D, Raithel J, Lilje B, Rapin N, Bagger FO, Jørgensen M, Andersen PR, Bertin N, Rackham O, Burroughs AM, Baillie JK, Ishizu Y, Shimizu Y, Furuhata E, Maeda S, Negishi Y, Mungall CJ, Meehan TF, Lassmann T, Itoh M, Kawaji H, Kondo N, Kawai J, Lennartsson A, Daub CO, Heutink P, Hume DA, Jensen TH, Suzuki H, Hayashizaki Y, Müller F, Forrest ARR, Carninci P, Rehli M, Sandelin A, The FC (2014) An atlas of active enhancers across human cell types and tissues. Nature 507:455-461. https://doi.org/10.1038/nature12787

Archibald HD, Ascha M, Gupta A, Megerian C, Otteson T (2019) Hearing loss in unilateral and bilateral enlarged vestibular aqueduct syndrome. Int J Pediatr Otorhinolaryngol 118:147-151. https://doi.org/10.1016/j.ijporl.2018.12.023

Arjmand EM, Webber A (2004) Audiometric findings in children with a large vestibular aqueduct. Arch Otolaryngol Head Neck Surg 130:1169-1174. https://doi.org/10.1001/archotol.130.10.1169

Ascha MS, Manzoor N, Gupta A, Semaan M, Megerian C, Otteson TD (2017) Vestibular aqueduct midpoint width and hearing loss in patients with an enlarged vestibular aqueduct. JAMA OtolaryngolHead \& Neck Surg 143:601-608. https://doi.org/10.1001/jamao to.2016.4522

Azaiez H, Yang T, Prasad S, Sorensen JL, Nishimura CJ, Kimberling WJ, Smith RJ (2007) Genotype-phenotype correlations for SLC26A4-related deafness. Hum Genet 122:451-457. https://doi. org/10.1007/s00439-007-0415-2

Azaiez H, Booth KT, Ephraim SS, Crone B, Black-Ziegelbein EA, Marini RJ, Shearer AE, Sloan-Heggen CM, Kolbe D, Casavant T, Schnieders MJ, Nishimura C, Braun T, Smith RJH (2018) Genomic landscape and mutational signatures of deafness-associated genes. Am J Hum Genet 103:484-497. https://doi.org/10. 1016/j.ajhg.2018.08.006

Boeva V, Popova T, Bleakley K, Chiche P, Cappo J, Schleiermacher G, Janoueix-Lerosey I, Delattre O, Barillot E (2012) ControlFREEC: a tool for assessing copy number and allelic content using next-generation sequencing data. Bioinformatics 28:423-425. https://doi.org/10.1093/bioinformatics/btr670

Boston M, Halsted M, Meinzen-Derr J, Bean J, Vijayasekaran S, Arjmand E, Choo D, Benton C, Greinwald J (2007) The large vestibular aqueduct: a new definition based on audiologic and computed tomography correlation. Otolaryngol Head Neck Surg 136:972-977. https://doi.org/10.1016/j.otohns.2006.12.011

Brameier M, Krings A, MacCallum RM (2007) NucPred-predicting nuclear localization of proteins. Bioinformatics 23:1159-1160. https://doi.org/10.1093/bioinformatics/btm066

Chaisson MJP, Sanders AD, Zhao X, Malhotra A, Porubsky D, Rausch T, Gardner EJ, Rodriguez OL, Guo L, Collins RL, Fan X, Wen J, Handsaker RE, Fairley S, Kronenberg ZN, Kong X, Hormozdiari F, Lee D, Wenger AM, Hastie AR, Antaki D, Anantharaman T, Audano PA, Brand H, Cantsilieris S, Cao H, Cerveira E, Chen C, Chen X, Chin C-S, Chong Z, Chuang NT, Lambert CC, Church DM, Clarke L, Farrell A, Flores J, Galeev T, Gorkin DU, Gujral M, Guryev V, Heaton WH, Korlach J, Kumar S, Kwon JY, Lam ET, Lee JE, Lee J, Lee W-P, Lee SP, Li S, Marks P, Viaud-Martinez K, Meiers S, Munson KM, Navarro FCP, Nelson BJ, Nodzak C, Noor A, Kyriazopoulou-Panagiotopoulou S, Pang AWC, Qiu Y, Rosanio G, Ryan M, Stütz A, Spierings DCJ, Ward A, Welch AE, Xiao M, Xu W, Zhang C, Zhu Q, Zheng-Bradley X, Lowy E, Yakneen S, McCarroll S, Jun G, Ding L, Koh CL, Ren B, Flicek P, Chen K, Gerstein MB, Kwok P-Y, Lansdorp PM, Marth GT, Sebat J, Shi X, Bashir A, Ye K, Devine SE, Talkowski ME, Mills
RE, Marschall T, Korbel JO, Eichler EE, Lee C (2019) Multiplatform discovery of haplotype-resolved structural variation in human genomes. Nat Commun 10:1784. https://doi.org/10.1038/ s41467-018-08148-z

Chao JR, Chattaraj P, Munjal T, Honda K, King KA, Zalewski CK, Chien WW, Brewer CC, Griffith AJ (2019) SLC26A4-linked CEVA haplotype correlates with phenotype in patients with enlargement of the vestibular aqueduct. BMC Med Genet 20:118. https://doi.org/10.1186/s12881-019-0853-4

Chattaraj P, Munjal T, Honda K, Rendtorff ND, Ratay JS, Muskett JA, Risso DS, Roux I, Gertz EM, Schaffer AA, Friedman TB, Morell RJ, Tranebjaerg L, Griffith AJ (2017) A common SLC26A4linked haplotype underlying non-syndromic hearing loss with enlargement of the vestibular aqueduct. J Med Genet 54:665-673. https://doi.org/10.1136/jmedgenet-2017-104721

Chen X, Schulz-Trieglaff O, Shaw R, Barnes B, Schlesinger F, Källberg M, Cox AJ, Kruglyak S, Saunders CT (2016) Manta: rapid detection of structural variants and indels for germline and cancer sequencing applications. Bioinformatics 32:1220-1222. https:// doi.org/10.1093/bioinformatics/btv710

Choi BY, Madeo AC, King KA, Zalewski CK, Pryor SP, Muskett JA, Nance WE, Butman JA, Brewer CC, Griffith AJ (2009) Segregation of enlarged vestibular aqueducts in families with non-diagnostic SLC26A4 genotypes. J Med Genet 46:856-861. https://doi. org/10.1136/jmg.2009.067892

de Bruijn SE, Smits JJ, Liu C, Lanting CP, Beynon AJ, Blankevoort J, Oostrik J, Koole W, de Vrieze E, Cremers CWRJ, Cremers FPM, Roosing S, Yntema HG, Kunst HPM, Zhao B, Pennings RJE, Kremer H (2021) A RIPOR2 in-frame deletion is a frequent and highly penetrant cause of adult-onset hearing loss. J Med Genet 58:96. https://doi.org/10.1136/jmedgenet-2020-106863

Dimitrieva S, Bucher P (2013) UCNEbase-a database of ultraconserved non-coding elements and genomic regulatory blocks. Nucleic Acids Res 41:D101-D109. https://doi.org/10.1093/nar/gks1092

Dou H, Xu J, Wang Z, Smith AN, Soleimani M, Karet FE, Greinwald JH Jr, Choo D (2004) Co-expression of pendrin, vacuolar H+ATPase alpha4-subunit and carbonic anhydrase II in epithelial cells of the murine endolymphatic sac. J Histochem Cytochem 52:1377-1384. https://doi.org/10.1177/002215540405201014

Dreos R, Ambrosini G, Cavin Périer R, Bucher P (2013) EPD and EPDnew, high-quality promoter resources in the next-generation sequencing era. Nucleic Acids Res 41:D157-D164. https://doi. org/10.1093/nar/gks1233

Dunham I, Kundaje A, Aldred SF, Collins PJ, Davis CA, Doyle F, Epstein CB, Frietze S, Harrow J, Kaul R, Khatun J, Lajoie BR, Landt SG, Lee B-K, Pauli F, Rosenbloom KR, Sabo P, Safi A, Sanyal A, Shoresh N, Simon JM, Song L, Trinklein ND, Altshuler RC, Birney E, Brown JB, Cheng C, Djebali S, Dong X, Dunham I, Ernst J, Furey TS, Gerstein M, Giardine B, Greven M, Hardison RC, Harris RS, Herrero J, Hoffman MM, Iyer S, Kellis M, Khatun J, Kheradpour P, Kundaje A, Lassmann T, Li Q, Lin X, Marinov GK, Merkel A, Mortazavi A, Parker SCJ, Reddy TE, Rozowsky J, Schlesinger F, Thurman RE, Wang J, Ward LD, Whitfield TW, Wilder SP, Wu W, Xi HS, Yip KY, Zhuang J, Bernstein BE, Birney E, Dunham I, Green ED, Gunter C, Snyder M, Pazin MJ, Lowdon RF, Dillon LAL, Adams LB, Kelly CJ, Zhang J, Wexler JR, Green ED, Good PJ, Feingold EA, Bernstein BE, Birney E, Crawford GE, Dekker J, Elnitski L, Farnham PJ, Gerstein M, Giddings MC, Gingeras TR, Green ED, Guigó R, Hardison RC, Hubbard TJ, Kellis M, Kent WJ, Lieb JD, Margulies EH, Myers RM, Snyder M, Stamatoyannopoulos JA, Tenenbaum SA et al (2012) An integrated encyclopedia of DNA elements in the human genome. Nature 489:57-74. https://doi.org/10.1038/nature11247

Enerbäck S, Nilsson D, Edwards N, Heglind M, Alkanderi S, Ashton E, Deeb A, Kokash FEB, Bakhsh ARA, Van't Hoff W, Walsh SB, D'Arco F, Daryadel A, Bourgeois S, Wagner CA, Kleta 
R, Bockenhauer D, Sayer JA (2018) Acidosis and Deafness in Patients with Recessive Mutations in FOXI1. J Am Soc Nephrol 29:1041-1048. https://doi.org/10.1681/ASN.2017080840

Everett LA, Glaser B, Beck JC, Idol JR, Buchs A, Heyman M, Adawi F, Hazani E, Nassir E, Baxevanis AD, Sheffield VC, Green ED (1997) Pendred syndrome is caused by mutations in a putative sulphate transporter gene (PDS). Nat Genet 17:411-422. https:// doi.org/10.1038/ng1297-411

Everett LA, Morsli H, Wu DK, Green ED (1999) Expression pattern of the mouse ortholog of the Pendred's syndrome gene (Pds) suggests a key role for pendrin in the inner ear. Proc Natl Acad Sci USA 96:9727-9732. https://doi.org/10.1073/pnas.96.17.9727

Fishilevich S, Nudel R, Rappaport N, Hadar R, Plaschkes I, Iny Stein T, Rosen N, Kohn A, Twik M, Safran M, Lancet D, Cohen D (2017) GeneHancer: genome-wide integration of enhancers and target genes in GeneCards. Database (oxford) 2017:bax028. https://doi. org/10.1093/database/bax028

Forli F, Lazzerini F, Auletta G, Bruschini L, Berrettini S (2021) Enlarged vestibular aqueduct and Mondini Malformation: audiological, clinical, radiologic and genetic features. Eur Arch Otorhinolaryngol 278:2305-2312. https://doi.org/10.1007/ s00405-020-06333-9

Fornes O, Castro-Mondragon JA, Khan A, van der Lee R, Zhang X, Richmond PA, Modi BP, Correard S, Gheorghe M, Baranašić D, Santana-Garcia W, Tan G, Chèneby J, Ballester B, Parcy F, Sandelin A, Lenhard B, Wasserman WW, Mathelier A (2020) JASPAR 2020: update of the open-access database of transcription factor binding profiles. Nucleic Acids Res 48:d87-d92. https://doi.org/ 10.1093/nar/gkz1001

Fraser GR (1965) Association of congenital deafness with goitre (pendred's syndrome): a study of 207 families. Ann Hum Genet 28:201-249. https://doi.org/10.1111/j.1469-1809.1964.tb00479.x

Gao T, Qian J (2020) EnhancerAtlas 2.0: an updated resource with enhancer annotation in 586 tissue/cell types across nine species. Nucleic Acids Res 48:d58-d64. https://doi.org/10.1093/nar/ gkz980

Genomes Project Consortium, Auton A, Brooks LD, Durbin RM, Garrison EP, Kang HM, Korbel JO, Marchini JL, McCarthy S, McVean GA, Abecasis GR (2015) A global reference for human genetic variation. Nature 526:68-74. https://doi.org/10.1038/natur e15393

Gopen Q, Zhou G, Whittemore K, Kenna M (2011) Enlarged vestibular aqueduct: review of controversial aspects. Laryngoscope 121:1971-1978. https://doi.org/10.1002/lary.22083

Govaerts PJ, Casselman J, Daemers K, De Ceulaer G, Somers T, Offeciers FE (1999) Audiological findings in large vestibular aqueduct syndrome. Int J Pediatr Otorhinolaryngol 51:157-164. https://doi.org/10.1016/s0165-5876(99)00268-2

Griffith AJ, Wangemann P (2011) Hearing loss associated with enlargement of the vestibular aqueduct: mechanistic insights from clinical phenotypes, genotypes, and mouse models. Hear Res 281:11-17. https://doi.org/10.1016/j.heares.2011.05.009

Hosoya M, Fujioka M, Sone T, Okamoto S, Akamatsu W, Ukai H, Ueda HR, Ogawa K, Matsunaga T, Okano H (2017) Cochlear cell modeling using disease-specific iPSCs unveils a degenerative phenotype and suggests treatments for congenital progressive hearing loss. Cell Rep 18:68-81. https://doi.org/10.1016/j.celrep. 2016.12.020

Hulander M, Kiernan AE, Blomqvist SR, Carlsson P, Samuelsson EJ, Johansson BR, Steel KP, Enerbäck S (2003) Lack of pendrin expression leads to deafness and expansion of the endolymphatic compartment in inner ears of Foxi1 null mutant mice. Development 130:2013-2025. https://doi.org/10.1242/dev.00376

Jackler RK, de la Cruz A (1989) The large vestibular aqueduct syndrome. Laryngoscope 99:1238-1243. https://doi.org/10.1288/ 00005537-198912000-00006
Jaganathan K, Kyriazopoulou Panagiotopoulou S, McRae JF, Darbandi SF, Knowles D, Li YI, Kosmicki JA, Arbelaez J, Cui W, Schwartz GB, Chow ED, Kanterakis E, Gao H, Kia A, Batzoglou S, Sanders SJ, Farh KK-H (2019) Predicting splicing from primary sequence with deep learning. Cell 176:535-548.e24. https://doi.org/10. 1016/j.cell.2018.12.015

Jonard L, Niasme-Grare M, Bonnet C, Feldmann D, Rouillon I, Loundon N, Calais C, Catros H, David A, Dollfus H, Drouin-Garraud V, Duriez F, Eliot MM, Fellmann F, Francannet C, GilbertDussardier B, Gohler C, Goizet C, Journel H, Mom T, ThuillierObstoy M-F, Couderc R, Garabédian EN, Denoyelle F, Marlin S (2010) Screening of SLC26A4, FOXI1 and KCNJ10 genes in unilateral hearing impairment with ipsilateral enlarged vestibular aqueduct. Int J Pediatr Otorhinolaryngol 74:1049-1053. https:// doi.org/10.1016/j.ijporl.2010.06.002

Karczewski KJ, Francioli LC, Tiao G, Cummings BB, Alföldi J, Wang Q, Collins RL, Laricchia KM, Ganna A, Birnbaum DP, Gauthier LD, Brand H, Solomonson M, Watts NA, Rhodes D, Singer-Berk M, England EM, Seaby EG, Kosmicki JA, Walters RK, Tashman K, Farjoun Y, Banks E, Poterba T, Wang A, Seed C, Whiffin N, Chong JX, Samocha KE, Pierce-Hoffman E, Zappala Z, O'Donnell-Luria AH, Minikel EV, Weisburd B, Lek M, Ware JS, Vittal C, Armean IM, Bergelson L, Cibulskis K, Connolly KM, Covarrubias M, Donnelly S, Ferriera S, Gabriel S, Gentry J, Gupta N, Jeandet T, Kaplan D, Llanwarne C, Munshi R, Novod S, Petrillo N, Roazen D, Ruano-Rubio V, Saltzman A, Schleicher M, Soto J, Tibbetts K, Tolonen C, Wade G, Talkowski ME, Neale BM, Daly MJ, MacArthur DG (2019) Variation across 141,456 human exomes and genomes reveals the spectrum of loss-offunction intolerance across human protein-coding genes. bioRxiv. https://doi.org/10.1101/531210

Kent WJ, Sugnet CW, Furey TS, Roskin KM, Pringle TH, Zahler AM, Haussler D (2002) The human genome browser at UCSC. Genome Res 12:996-1006. https://doi.org/10.1101/gr.229102

Khan A, Zhang X (2016) dbSUPER: a database of super-enhancers in mouse and human genome. Nucleic Acids Res 44:D164-D171. https://doi.org/10.1093/nar/gkv1002

Khan M, Cornelis SS, Pozo-Valero MD, Whelan L, Runhart EH, Mishra K, Bults F, AlSwaiti Y, AlTalbishi A, De Baere E, Banfi S, Banin E, Bauwens M, Ben-Yosef T, Boon CJF, van den Born LI, Defoort S, Devos A, Dockery A, Dudakova L, Fakin A, Farrar GJ, Sallum JMF, Fujinami K, Gilissen C, Glavač D, Gorin MB, Greenberg J, Hayashi T, Hettinga YM, Hoischen A, Hoyng CB, Hufendiek K, Jägle H, Kamakari S, Karali M, Kellner U, Klaver CCW, Kousal B, Lamey TM, MacDonald IM, Matynia A, McLaren TL, Mena MD, Meunier I, Miller R, Newman H, Ntozini B, Oldak M, Pieterse M, Podhajcer OL, Puech B, Ramesar R, Rüther K, Salameh M, Salles MV, Sharon D, Simonelli F, Spital G, Steehouwer M, Szaflik JP, Thompson JA, Thuillier C, Tracewska AM, van Zweeden M, Vincent AL, Zanlonghi X, Liskova P, Stöhr H, Roach JND, Ayuso C, Roberts L, Weber BHF, Dhaenens CM, Cremers FPM (2020) Resolving the dark matter of ABCA4 for 1054 Stargardt disease probands through integrated genomics and transcriptomics. Genet Med 22:1235-1246. https://doi.org/ 10.1038/s41436-020-0787-4

Kim M-A, Kim SH, Ryu N, Ma J-H, Kim Y-R, Jung J, Hsu C-J, Choi JY, Lee K-Y, Wangemann P, Bok J, Kim U-K (2019) Gene therapy for hereditary hearing loss by SLC26A4 mutations in mice reveals distinct functional roles of pendrin in normal hearing. Theranostics 9:7184-7199. https://doi.org/10.7150/thno.38032

Kircher M, Witten DM, Jain P, O'Roak BJ, Cooper GM, Shendure J (2014) A general framework for estimating the relative pathogenicity of human genetic variants. Nat Genet 46:310-315. https:// doi.org/10.1038/ng.2892

Krumm N, Sudmant PH, Ko A, O'Roak BJ, Malig M, Coe BP, Project NES, Quinlan AR, Nickerson DA, Eichler EE (2012) Copy 
number variation detection and genotyping from exome sequence data. Genome Res 22:1525-1532. https://doi.org/10.1101/gr. 138115.112

Landa P, Differ A-M, Rajput K, Jenkins L, Bitner-Glindzicz M (2013) Lack of significant association between mutations of KCNJ10 or FOXI1 and SLC26A4 mutations in pendred syndrome/enlarged vestibular aqueducts. BMC Med Genet 14:85. https://doi.org/10. 1186/1471-2350-14-85

Landrum MJ, Lee JM, Benson M, Brown GR, Chao C, Chitipiralla S, Gu B, Hart J, Hoffman D, Jang W, Karapetyan K, Katz K, Liu C, Maddipatla Z, Malheiro A, McDaniel K, Ovetsky M, Riley G, Zhou G, Holmes JB, Kattman BL, Maglott DR (2018) ClinVar: improving access to variant interpretations and supporting evidence. Nucleic Acids Res 46:D1062-D1067. https://doi.org/10. 1093/nar/gkx1153

Lee HJ, Jung J, Shin JW, Song MH, Kim SH, Lee JH, Lee KA, Shin S, Kim UK, Bok J, Lee KY, Choi JY, Park HJ (2014) Correlation between genotype and phenotype in patients with bi-allelic SLC26A4 mutations. Clin Genet 86:270-275. https://doi.org/10. $1111 /$ cge. 12273

Lenth RV (2016) Least-squares means: the R package lsmeans. J Stat Softw 69:1-33. https://doi.org/10.18637/jss.v069.i01

Levy-Sakin M, Pastor S, Mostovoy Y, Li L, Leung AKY, McCaffrey J, Young E, Lam ET, Hastie AR, Wong KHY, Chung CYL, Ma W, Sibert J, Rajagopalan R, Jin N, Chow EYC, Chu C, Poon A, Lin C, Naguib A, Wang W-P, Cao H, Chan T-F, Yip KY, Xiao M, Kwok P-Y (2019) Genome maps across 26 human populations reveal population-specific patterns of structural variation. Nat Commun 10:1025. https://doi.org/10.1038/s41467-019-08992-7

Li H, Durbin R (2009) Fast and accurate short read alignment with Burrows-Wheeler transform. Bioinformatics 25:1754-1760. https://doi.org/10.1093/bioinformatics/btp324

Li M, Nishio S-y, Naruse C, Riddell M, Sapski S, Katsuno T, Hikita T, Mizapourshafiyi F, Smith FM, Cooper LT, Lee MG, Asano M, Boettger T, Krueger M, Wietelmann A, Graumann J, Day BW, Boyd AW, Offermanns S, Kitajiri S-i, Usami S-i, Nakayama M (2020) Digenic inheritance of mutations in EPHA2 and SLC26A4 in Pendred syndrome. Nat Commun 11:1343. https://doi.org/10. 1038/s41467-020-15198-9

Liu YL, Wang LL, Wen J, Mei LY, He CF, Jiang L, Feng Y (2021) Application value of high-throughput gene copy number variation detection in the diagnosis of enlarged vestibular aqueduct. Zhonghua Yi Xue Za Zhi 101:103-107. https://doi.org/10.3760/ cma.j.cn112137-20201010-02794

Mantere T, Neveling K, Pebrel-Richard C, Benoist M, van der Zande G, Kater-Baats E, Baatout I, van Beek R, Yammine T, Oorsprong M, Hsoumi F, Olde-Weghuis D, Majdali W, Vermeulen S, Pauper M, Lebbar A, Stevens-Kroef M, Sanlaville D, Dupont JM, Smeets D, Hoischen A, Schluth-Bolard C, El Khattabi L (2021) Optical genome mapping enables constitutional chromosomal aberration detection. Am J Hum Genet. https://doi.org/10.1016/j.ajhg.2021. 05.012

McKenna A, Hanna M, Banks E, Sivachenko A, Cibulskis K, Kernytsky A, Garimella K, Altshuler D, Gabriel S, Daly M, DePristo MA (2010) The genome analysis toolkit: a Mapreduce framework for analyzing next-generation DNA sequencing data. Genome Res 20:1297-1303. https://doi.org/10.1101/gr.107524.110

Mey K, Muhamad AA, Tranebjaerg L, Rendtorff ND, Rasmussen SH, Bille M, Cayé-Thomasen P (2019) Association of SLC26A4 mutations, morphology, and hearing in pendred syndrome and NSEVA. Laryngoscope 129:2574-2579. https://doi.org/10.1002/lary.27319

Miyagawa M, Nishio S-y, Usami S-i, The Deafness Gene Study C (2014) Mutation spectrum and genotype-phenotype correlation of hearing loss patients caused by SLC26A4 mutations in the Japanese: a large cohort study. J Hum Genet 59:262-268. https:// doi.org/10.1038/jhg.2014.12
Morton CC, Nance WE (2006) Newborn hearing screening-a silent revolution. N Engl J Med 354:2151-2164. https://doi.org/10.1056/ NEJMra050700

Neveling K, Mensenkamp AR, Derks R, Kwint M, Ouchene H, Steehouwer M, van Lier B, Bosgoed E, Rikken A, Tychon M, Zafeiropoulou D, Castelein S, Hehir-Kwa J, Tjwan Thung D, Hofste T, Lelieveld SH, Bertens SM, Adan IB, Eijkelenboom A, Tops BB, Yntema H, Stokowy T, Knappskog PM, Høberg-Vetti H, Steen VM, Boyle E, Martin B, Ligtenberg MJ, Shendure J, Nelen MR, Hoischen A (2017) BRCA testing by single-molecule molecular inversion probes. Clin Chem 63:503-512. https://doi.org/10.1373/ clinchem.2016.263897

Neveling K, Mantere T, Vermeulen S, Oorsprong M, van Beek R, Kater-Baats E, Pauper M, van der Zande G, Smeets D, Weghuis DO, Stevens-Kroef M, Hoischen A (2021) Next-generation cytogenetics: comprehensive assessment of 52 hematological malignancy genomes by optical genome mapping. Am J Hum Genet. https://doi.org/10.1016/j.ajhg.2021.06.001

Oonk AM, Leijendeckers JM, Huygen PL, Schraders M, del Campo M, del Castillo I, Tekin M, Feenstra I, Beynon AJ, Kunst HP, Snik AF, Kremer H, Admiraal RJ, Pennings RJ (2014) Similar phenotypes caused by mutations in OTOG and OTOGL. Ear Hear 35:e84-91. https://doi.org/10.1097/aud.0000000000 000008

Oza AM, DiStefano MT, Hemphill SE, Cushman BJ, Grant AR, Siegert RK, Shen J, Chapin A, Boczek NJ, Schimmenti LA, Murry JB, Hasadsri L, Nara K, Kenna M, Booth KT, Azaiez H, Griffith A, Avraham KB, Kremer H, Rehm HL, Amr SS, Abou Tayoun AN (2018) Expert specification of the ACMG/AMP variant interpretation guidelines for genetic hearing loss. Hum Mutat 39:15931613. https://doi.org/10.1002/humu.23630

Pedemonte N, Caci E, Sondo E, Caputo A, Rhoden K, Pfeffer U, Di Candia M, Bandettini R, Ravazzolo R, Zegarra-Moran O, Galietta LJ (2007) Thiocyanate transport in resting and IL-4-stimulated human bronchial epithelial cells: role of pendrin and anion channels. J Immunol 178:5144-5153. https://doi.org/10.4049/jimmu nol.178.8.5144

Pedersen BS, Quinlan AR (2018) Mosdepth: quick coverage calculation for genomes and exomes. Bioinformatics 34:867-868. https:// doi.org/10.1093/bioinformatics/btx699

Pique LM, Brennan ML, Davidson CJ, Schaefer F, Greinwald J Jr, Schrijver I (2014) Mutation analysis of the SLC26A4, FOXI1 and KCNJ10 genes in individuals with congenital hearing loss. PeerJ 2:e384. https://doi.org/10.7717/peerj.384

Pryor SP, Madeo AC, Reynolds JC, Sarlis NJ, Arnos KS, Nance WE, Yang Y, Zalewski CK, Brewer CC, Butman JA, Griffith AJ (2005) SLC26A4/PDS genotype-phenotype correlation in hearing loss with enlargement of the vestibular aqueduct (EVA): evidence that Pendred syndrome and non-syndromic EVA are distinct clinical and genetic entities. J Med Genet 42:159-165. https://doi.org/10. 1136/jmg.2004.024208

Rah YC, Kim AR, Koo J-W, Lee JH, Oh S-h, Choi BY (2015) Audiologic presentation of enlargement of the vestibular aqueduct according to the SLC26A4 genotypes. Laryngoscope 125:E216E222. https://doi.org/10.1002/lary.25079

Robinson JT, Thorvaldsdóttir H, Winckler W, Guttman M, Lander ES, Getz G, Mesirov JP (2011) Integrative genomics viewer. Nat Biotechnol 29:24-26. https://doi.org/10.1038/nbt.1754

Royaux IE, Suzuki K, Mori A, Katoh R, Everett LA, Kohn LD, Green ED (2000) Pendrin, the protein encoded by the Pendred syndrome gene (PDS), is an apical porter of iodide in the thyroid and is regulated by thyroglobulin in FRTL-5 cells. Endocrinology 141:839845. https://doi.org/10.1210/endo.141.2.7303

Royaux IE, Wall SM, Karniski LP, Everett LA, Suzuki K, Knepper MA, Green ED (2001) Pendrin, encoded by the Pendred syndrome gene, resides in the apical region of renal intercalated cells 
and mediates bicarbonate secretion. Proc Natl Acad Sci U S A 98:4221-4226. https://doi.org/10.1073/pnas.071516798

Royaux IE, Belyantseva IA, Wu T, Kachar B, Everett LA, Marcus DC, Green ED (2003) Localization and functional studies of pendrin in the mouse inner ear provide insight about the etiology of deafness in pendred syndrome. J Assoc Res Otolaryngol 4:394-404. https://doi.org/10.1007/s10162-002-3052-4

Saeed HS, Kenth J, Black G, Saeed SR, Stivaros S, Bruce IA (2021) Hearing loss in enlarged vestibular aqueduct: a prognostic factor systematic review of the literature. Otol Neurotol. https://doi.org/ 10.1097/MAO.0000000000002843

Sangermano R, Khan M, Cornelis SS, Richelle V, Albert S, Garanto A, Elmelik D, Qamar R, Lugtenberg D, van den Born LI, Collin RWJ, Cremers FPM (2018) ABCA4 midigenes reveal the full splice spectrum of all reported noncanonical splice site variants in Stargardt disease. Genome Res 28:100-110. https://doi.org/10. 1101/gr.226621.117

Schwarz JM, Cooper DN, Schuelke M, Seelow D (2014) MutationTaster2: mutation prediction for the deep-sequencing age. Nat Methods 11:361. https://doi.org/10.1038/nmeth.2890

Sloan-Heggen CM, Bierer AO, Shearer AE, Kolbe DL, Nishimura CJ, Frees KL, Ephraim SS, Shibata SB, Booth KT, Campbell CA, Ranum PT, Weaver AE, Black-Ziegelbein EA, Wang D, Azaiez $\mathrm{H}$, Smith RJH (2016) Comprehensive genetic testing in the clinical evaluation of 1119 patients with hearing loss. Hum Genet 135:441-450. https://doi.org/10.1007/s00439-016-1648-8

Song MH, Shin J-W, Park H-J, Lee K-A, Kim Y, Kim U-K, Jeon JH, Choi JY (2014) Intrafamilial phenotypic variability in families with biallelic SLC26A4 mutations. Laryngoscope 124:E194E202. https://doi.org/10.1002/lary.24504

Suzuki H, Oshima A, Tsukamoto K, Abe S, Kumakawa K, Nagai K, Satoh H, Kanda Y, Iwasaki S, Usami S (2007) Clinical characteristics and genotype-phenotype correlation of hearing loss patients with SLC26A4 mutations. Acta Otolaryngol 127:1292-1297. https://doi.org/10.1080/00016480701258739

van Beeck Calkoen EA, Sanchez Aliaga E, Merkus P, Smit CF, van de Kamp JM, Mulder MF, Goverts ST, Hensen EF (2017) High prevalence of abnormalities on CT and MR imaging in children with unilateral sensorineural hearing loss irrespective of age or degree of hearing loss. Int J Pediatr Otorhinolaryngol 97:185-191. https://doi.org/10.1016/j.ijporl.2017.04.002

van Beeck Calkoen EA, Merkus P, Goverts ST, van de Kamp JM, Mulder MF, Sanchez Aliaga E, Hensen EF (2018) Evaluation of the outcome of CT and MR imaging in pediatric patients with bilateral sensorineural hearing loss. Int J Pediatr Otorhinolaryngol 108:180-185. https://doi.org/10.1016/j.ijporl.2018.02.022

van Beeck Calkoen EA, Engel MSD, van de Kamp JM, Yntema HG, Goverts ST, Mulder MF, Merkus P, Hensen EF (2019) The etiological evaluation of sensorineural hearing loss in children. Eur J Pediatr 178:1195-1205. https://doi.org/10.1007/ s00431-019-03379-8

van Camp G, Smith R (2021) Hereditary Hearing Loss Homepage. https://hereditaryhearingloss.org

van der Ploeg CP, Uilenburg NN, Kauffman-de Boer MA, OudesluysMurphy AM, Verkerk PH (2012) Newborn hearing screening in youth health care in the Netherlands: National results of implementation and follow-up. Int J Audiol 51:584-590. https://doi.org/ 10.3109/14992027.2012.684402

Vaser R, Adusumalli S, Leng SN, Sikic M, Ng PC (2015) SIFT missense predictions for genomes. Nat Protoc 11:1. https://doi.org/ 10.1038/nprot.2015.123
Visel A, Minovitsky S, Dubchak I, Pennacchio LA (2007) VISTA Enhancer Browser-a database of tissue-specific human enhancers. Nucleic Acids Res 35:D88-D92. https://doi.org/10.1093/nar/ gk1822

Wangemann P (2011) The role of pendrin in the development of the murine inner ear. Cell Physiol Biochem 28:527-534. https://doi. org/10.1159/000335113

Wangemann P, Nakaya K, Wu T, Maganti RJ, Itza EM, Sanneman JD, Harbidge DG, Billings S, Marcus DC (2007) Loss of cochlear $\mathrm{HCO}_{3}$ - secretion causes deafness via endolymphatic acidification and inhibition of $\mathrm{Ca} 2+$ reabsorption in a Pendred syndrome mouse model. Am J Physiol Renal Physiol 292:F1345-F1353. https://doi.org/10.1152/ajprenal.00487.2006

Wesdorp M, Murillo-Cuesta S, Peters T, Celaya AM, Oonk A, Schraders M, Oostrik J, Gomez-Rosas E, Beynon AJ, Hartel BP, Okkersen K, Koenen H, Weeda J, Lelieveld S, Voermans NC, Joosten I, Hoyng CB, Lichtner P, Kunst HPM, Feenstra I, de Bruijn SE, Consortium D, Admiraal RJC, Yntema HG, van Wijk E, Del Castillo I, Serra P, Varela-Nieto I, Pennings RJE, Kremer H (2018) MPZL2, encoding the epithelial junctional protein myelin protein zero-like 2 , is essential for hearing in man and mouse. Am J Hum Genet 103:74-88. https://doi.org/10.1016/j. ajhg.2018.05.011

Wilderman A, VanOudenhove J, Kron J, Noonan JP, Cotney J (2018) High-resolution epigenomic atlas of human embryonic craniofacial development. Cell Rep 23:1581-1597. https://doi.org/10. 1016/j.celrep.2018.03.129

Xie H, Wang M, Bischof J, Bonaldo MdF, Soares MB (2009) SNPbased prediction of the human germ cell methylation landscape. Genomics 93:434-440. https://doi.org/10.1016/j.ygeno.2009.01. 005

Yang T, Vidarsson H, Rodrigo-Blomqvist S, Rosengren SS, Enerback S, Smith RJ (2007) Transcriptional control of SLC26A4 is involved in Pendred syndrome and nonsyndromic enlargement of vestibular aqueduct (DFNB4). Am J Hum Genet 80:1055-1063. https://doi.org/10.1086/518314

Yang T, Gurrola JG, Wu H, Chiu SM, Wangemann P, Snyder PM, Smith RJH (2009) Mutations of KCNJ10 together with mutations of SLC26A4 Cause digenic nonsyndromic hearing loss associated with enlarged vestibular aqueduct syndrome. Am J Hum Genet 84:651-657. https://doi.org/10.1016/j.ajhg.2009.04.014

Yariz KO, Duman D, Zazo Seco C, Dallman J, Huang M, Peters TA, Sirmaci A, Lu N, Schraders M, Skromne I, Oostrik J, Diaz-Horta O, Young JI, Tokgoz-Yilmaz S, Konukseven O, Shahin H, Hetterschijt L, Kanaan M, Oonk AM, Edwards YJ, Li H, Atalay S, Blanton S, Desmidt AA, Liu XZ, Pennings RJ, Lu Z, Chen ZY, Kremer H, Tekin M (2012) Mutations in OTOGL, encoding the inner ear protein otogelin-like, cause moderate sensorineural hearing loss. Am J Hum Genet 91:872-882. https://doi.org/10.1016/j. ajhg.2012.09.011

Zerbino DR, Wilder SP, Johnson N, Juettemann T, Flicek PR (2015) The Ensembl Regulatory Build. Genome Biol 16:56. https://doi. org/10.1186/s13059-015-0621-5

Publisher's Note Springer Nature remains neutral with regard to jurisdictional claims in published maps and institutional affiliations. 


\section{Authors and Affiliations}

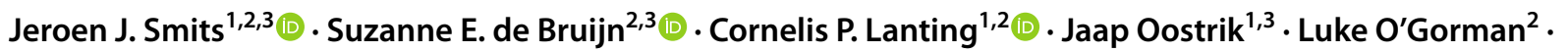
Tuomo Mantere $^{2,4}$. DOOFNL Consortium • Frans P. M. Cremers ${ }^{2,3}$ - Susanne Roosing ${ }^{2,3} \cdot$ Helger G. Yntema ${ }^{2}$. Erik de Vrieze $^{1,3} \cdot$ Ronny Derks $^{2} \cdot$ Alexander Hoischen $^{2,5,6,7} \cdot$ Sjoert A. H. Pegge ${ }^{8} \cdot$ Kornelia Neveling $^{2}$. Ronald J. E. Pennings ${ }^{1,3}$ (D) Hannie Kremer ${ }^{1,2,3}$ (1)

1 Hearing and Genes, Department of Otorhinolaryngology, Radboud University Medical Center, Nijmegen,

The Netherlands

2 Department of Human Genetics, Radboud University Medical Center, Internal Postal Code 855, P.O. Box 9101, 6500 HB Nijmegen, The Netherlands

3 Donders Institute for Brain, Cognition and Behaviour, Radboud University Medical Center, Nijmegen, The Netherlands

4 Laboratory of Cancer Genetics and Tumor Biology, Cancer and Translational Medicine Research Unit and Biocenter Oulu, University of Oulu, Oulu, Finland
5 Center for Infectious Diseases (RCI), Department of Internal Medicine, Radboud University Medical Center, Nijmegen, The Netherlands

6 Radboud Institute for Molecular Life Sciences, Radboud University Medical Center, Nijmegen, The Netherlands

7 Radboud Expertise Center for Immunodeficiency and Autoinflammation and Center for Infectious Disease (RCI), Radboud University Medical Center, Nijmegen, The Netherlands

8 Department of Radiology and Nuclear Medicine, Radboud University Medical Center, Nijmegen, The Netherlands 